Article

\title{
Development of a Versatile, Near Full Genome Amplification and Sequencing Approach for a Broad Variety of HIV-1 Group M Variants
}

\author{
Andrew N. Banin ${ }^{1,2}$, Michael Tuen ${ }^{1}$, Jude S. Bimela ${ }^{1,3}$, Marcel Tongo ${ }^{4} \mathbb{C}$, Paul Zappile ${ }^{1}$, \\ Alireza Khodadadi-Jamayran ${ }^{5}$, Aubin J. Nanfack ${ }^{1,6,7}$, Josephine Meli ${ }^{6}$, Xiaohong Wang ${ }^{8}$, \\ Dora Mbanya ${ }^{9}$, Jeanne Ngogang ${ }^{2}$, Adriana Heguy ${ }^{1}$, Phillipe N. Nyambi ${ }^{1,8,+}$, \\ Charles Fokunang ${ }^{10}$ and Ralf Duerr ${ }^{1,8, *}$ \\ 1 Department of Pathology, New York University School of Medicine, New York, NY 10016, USA; \\ andybanin@gmail.com (A.N.B.); Michael.Tuen@nyumc.org (M.T.); bimelajude@gmail.com (J.S.B.); \\ Paul.Zappile@nyumc.org (P.Z.); a_nanfack@yahoo.fr (A.J.N.); Adriana.Heguy@nyumc.org (A.H.); \\ camacf01@nyumc.org (P.N.N.) \\ 2 Faculty of Medicine and Biomedical Sciences, Department of Biochemistry, University of Yaoundé 1, \\ Yaoundé BP 1364, Cameroon; jngogang@yahoo.fr \\ 3 Faculty of Science, Department of Biochemistry, Yaoundé BP 1364, Cameroon \\ 4 Center of Research for Emerging and Re-Emerging Diseases (CREMER), Institute of Medical Research and \\ Study of Medicinal Plants, Yaoundé BP 906, Cameroon; marcel.tongo@gmail.com \\ 5 Applied Bioinformatics Laboratories (ABL) and Genome Technology Center (GTC), Division of Advanced \\ Research Technologies (DART), New York University Langone Medical Center, New York, NY 10016, USA; \\ alireza.khodadadi-jamayran@nyumc.org \\ 6 Medical Diagnostic Center, Yaoundé BP 15810,Cameroon; jmeli_cm@yahoo.fr \\ 7 Chantal Biya International Reference Center for Research on HIV/AIDS Prevention and Management, \\ Messa Yaoundé BP 3077, Cameroon \\ 8 Manhattan Veterans Affairs New York Harbor Healthcare System, New York, NY 10010, USA; \\ Xiaohong.Wang@va.gov \\ 9 Faculty of Medicine and Biomedical Sciences, Department of Microbiology, Parasitology and Infectious \\ Diseases, University of Yaoundé 1, Yaoundé BP 1364, Cameroon; dmbanya1@yahoo.co.uk \\ 10 Faculty of Medicine and Biomedical Sciences, Department of Pharmacotoxicology \& Pharmacokinetics, \\ University of Yaoundé 1, Yaoundé BP 1364, Cameroon; charlesfokunang@yahoo.co.uk \\ * Correspondence: Ralf.Duerr@nyumc.org; Tel.: +1-212-263-4159 \\ + Deceased.
}

Received: 5 March 2019; Accepted: 27 March 2019; Published: 1 April 2019

check for updates

\begin{abstract}
Near full genome sequencing (NFGS) of HIV-1 is required to assess the genetic composition of HIV-1 strains comprehensively. Population-wide, it enables a determination of the heterogeneity of HIV-1 and the emergence of novel/recombinant strains, while for each individual it constitutes a diagnostic instrument to assist targeted therapeutic measures against viral components. There is still a lack of robust and adaptable techniques for efficient NFGS from miscellaneous HIV-1 subtypes. Using rational primer design, a broad primer set was developed for the amplification and sequencing of diverse HIV-1 group M variants from plasma. Using pure subtypes as well as diverse, unique recombinant forms (URF), variable amplicon approaches were developed for NFGS comprising all functional genes. Twenty-three different genomes composed of subtypes A (A1), B, F (F2), G, CRF01_AE, CRF02_AG, and CRF22_01A1 were successfully determined. The NFGS approach was robust irrespective of viral loads ( $\geq 306$ copies $/ \mathrm{mL}$ ) and amplification method. Third-generation sequencing (TGS), single genome amplification (SGA), cloning, and bulk sequencing yielded similar outcomes concerning subtype composition and recombinant breakpoint patterns. The introduction of a simple and versatile near full genome amplification, sequencing, and cloning method enables broad application in phylogenetic studies of diverse HIV-1 subtypes and can contribute to personalized HIV therapy and diagnosis.
\end{abstract}


Keywords: Near full genome amplification and sequencing; HIV-1 group M subtype-independent approach; rational primer design; single-genome amplification (SGA); third-generation sequencing (TGS); bulk sequencing and cloning

\section{Introduction}

HIV-1 full genome sequencing is a challenging task due to the broad degree of HIV-1 genomic diversity worldwide. Four major groups of HIV-1 exist, groups $\mathrm{M}, \mathrm{N}, \mathrm{O}$, and P [1-3], which are highly divergent and trace back to separate cross-species transmission events from primates to humans [4]. HIV-1 group $\mathrm{M}$ has spread globally, causing more than $85 \%$ of global HIV infections and can be subdivided into nine subtypes (A-D, F-H, J, and K), at least six sub-subtypes of A and F (A1-A6, F1-F2), currently at least 98 circulating recombinant forms (CRFs) [5], and numerous unique recombinant forms (URFs) [6]. CRFs and URFs are composed of two or more (sub)-subtypes; while CRFs have been identified in at least three epidemiologically unlinked individuals, URFs are defined as recombinants without evidence of onward transmission [5]. The continuous emergence of novel HIV-1 M strains [6-9] including sequences that remain unclassified or can be attributed to ancient strains [10] poses a significant challenge for HIV-1 molecular surveillance, diagnosis, and therapy [11,12]. Consequently, robust and versatile amplification and sequencing protocols are needed that apply to such strains over the near full genome (NFG).

The vast majority of sequences in the Los Alamos National Library (LANL) HIV sequence database are derived from partial genome sequencing [13]. Partial genome sequencing obscures subtype determinations and limits the identification of epidemiologic signatures and recombination breakpoints, which can be distributed across the entire viral genome [14,15]. To overcome these limitations, PCR-based near full genome sequencing (NFGS) protocols have been introduced, which were mostly applied in cohorts restricted to one or a few subtypes [16-20]. Protocols have been optimized for next-generation sequencing (NGS) [21,22], or the use of oligonucleotide probes combined with real-time PCR $[23,24]$. The coverage of multiple subtypes has been addressed by universal NFGS approaches $[22,25]$. Universal approaches rely on primer binding to semi-conserved regions in the HIV genome, and limited coverage and efficiencies can still occur depending on viral load and subtype. The combination of NGS with HIV-specific probes increased detection sensitivity and sequencing depth [26]; however, the detection of emerging and rapidly evolving strains is expected to be challenging. NGS approaches provide large-scale sequencing with in-depth coverage and analyses of minority variants; however, their usage is limited in resource-constrained settings due to the required equipment and expertise, and do not allow downstream processing of the amplicons and cloning. There is still a need for robust and straightforward NFGS protocols suited for a broad diversity of HIV-1 M subtypes and the generation of NFG amplicons adaptable to downstream biological applications.

A flexible NFGS approach has therefore been established by our team using rationally designed primers that bind at highly conserved domains across major HIV-1 group M subtypes. The set of primers enables nested PCRs to span single or multiple functional gene regions. It provides NFG amplification and sequencing through one-amplicon, two-amplicon or multiple-amplicon approaches. Pure HIV-1 M subtypes and highly diverse HIV-1 M URFs from Cameroon, characterized in detail in Banin et al. [27], were used to validate the protocol, which was applied to bulk sequencing, cloning, single-genome amplification (SGA), and third-generation sequencing (TGS).

\section{Materials and Methods}

\subsection{Ethical Clearance}

This study was conducted in accordance with the Declaration of Helsinki and the protocol was approved by the Institutional Ethical Review Board of the Cameroon Ministry of Public Health and by 
the Institutional Review Board at New York University School of Medicine (NYUSoM), New York, USA on April 6, 2018 (protocol: i09-0431). Before sample collection, informed consent was obtained from the study participants, who were all part of a cohort of HIV positive individuals; this cohort is monitored at the Medical Diagnostic Center (MDC) in Yaoundé, Cameroon in collaboration with the New York University School of Medicine (NYUSoM), New York, USA.

\subsection{Study Samples}

Whole blood samples were collected at the MDC between 2000 and 2015. They were shipped under standard regulatory conditions for biological materials to NYUSoM for processing of plasma and peripheral blood mononuclear cells (PBMCs) using Ficoll gradient centrifugation (Histopaque, Sigma-Aldrich, St. Louis, MO, USA), and stored at $-80^{\circ} \mathrm{C}$. Study samples were selected based on previously identified URF sequences through partial genome sequencing in our group and on the availability of plasma volumes $\geq 500 \mu \mathrm{L}$ [28-30].

\subsection{RNA Extraction}

Viral RNA was extracted from $500 \mu \mathrm{L}$ HIV-1 positive plasma using QIAamp Viral RNA Minikit (Qiagen, Valencia, CA, USA). Virions were concentrated by ultracentrifugation at $14,000 \times g$ for $2 \mathrm{~h}$ at $4{ }^{\circ} \mathrm{C}$. All but $140 \mu \mathrm{L}$ of the supernatant was removed before addition of lysis buffer and subsequent RNA extraction according to the manufacturer's instructions. Extracted RNA ( $30 \mu \mathrm{L})$ was either immediately reverse transcribed or stored at $-80^{\circ} \mathrm{C}$.

\section{4. cDNA Synthesis}

Reverse transcription of RNA was performed using SuperScript III (Life Technologies, Carlsbad, CA, USA) with primer OFM19 [31] corresponding to HXB2 position 9632-9604. If amplicons within the $5^{\prime}$ half of the HIV-1 genome could not be obtained using cDNA generated with OFM19 primer, HIV 6352 rev [25] was used as an alternative. For the generation of cDNA, $5.25 \mu \mathrm{L}$ nuclease-free water (Promega) was mixed with $0.75 \mu \mathrm{L}$ reverse primer OFM19 or HIV $6352 \mathrm{rev}(20 \mu \mathrm{M}), 3 \mu \mathrm{L}(10 \mathrm{mM})$ dNTP mix and $30 \mu \mathrm{L}$ extracted template RNA. The mix was incubated at $65{ }^{\circ} \mathrm{C}$ for $5 \mathrm{~min}$ and removed on ice for $1 \mathrm{~min} .12 \mu \mathrm{L} 5 \times$ first strand buffer, $3 \mu \mathrm{L}$ (100 mM) DTT solution, $3 \mu \mathrm{L}$ ( $40 \mathrm{U} / \mu \mathrm{L}$ ) RNaseOUT, and $3 \mu \mathrm{L}(200 \mathrm{U} / \mu \mathrm{L})$ SuperScript III Reverse Transcriptase were added to the mix to get a total volume of $60 \mu \mathrm{L}$. The mix was vortexed and incubated at $50{ }^{\circ} \mathrm{C}$ for $1 \mathrm{~h}$ followed by an increase to $55^{\circ} \mathrm{C}$ for $1 \mathrm{~h}$. SuperScript III Reverse Transcriptase was inactivated at $70^{\circ} \mathrm{C}$ for $15 \mathrm{~min}$. Remaining RNA was digested by adding $3 \mu \mathrm{L}$ RNase $\mathrm{H}(2 \mathrm{U} / \mu \mathrm{L})$ and incubation at $37^{\circ} \mathrm{C}$ for $20 \mathrm{~min}$.

\subsection{Primer Design}

The rational design of universal HIV-1 group $\mathrm{M}$ amplification and sequencing primers was based on full genome multiple sequence alignments with reference strains downloaded from the LANL database. Our approach is related to PrimerDesign-M, an alignment-based primer design tool from the LANL database, which also served as the first guide to identify appropriate genomic regions for some of our primers. Generally, most primers were designed manually based on sequence alignments and primer criteria as follows. An HIV-1 full genome alignment comprised of 480 reference sequences from all major group $\mathrm{M}$ (sub)-subtypes and CRFs [32] was shortened to a representative 40 strain-panel. The latter included four references per eight (sub)-subtypes A1, A2, B, C, D, F1, F2, G, and two CRFs, 01_AE, and 02_AG (Results 3.2), which make up to the most dominant (sub-)subtypes/CRFs prevailing the five inhabited continents of the world.

The procedure was similar for the design of amplification and sequencing primers with the only difference of targeted regions. Amplification primers mostly targeted conserved domains adjacent or at the ends of the genes of interest. Sequencing primers had no spatial constraints; however, appropriate distances ( $\sim 500 \mathrm{bp}$ ) between consecutive primer binding sites should provide sufficient sequence overlap between the multiple complementary sequence fragments ( $\geq 100$ bp overlap) while aiming 
for the lowest possible number of primers to cover NFGS. Preferentially, primers were designed to have a length of $18-30$ base pairs with $40-60 \%$ G/C content and a melting temperature $(\mathrm{Tm})$ of $50-65{ }^{\circ} \mathrm{C}$. Primer pairs should be within $5{ }^{\circ} \mathrm{C}$ difference in Tm and exempt of complementary regions to avoid heterodimers. Primers with long stretches of identical base pairs (especially $\mathrm{G}$ and $\mathrm{C}$ ), hairpin structures, or self-complementary regions (homodimers) were avoided, as can be analyzed with a primer design software such as IDT OligoAnalyzer (https://www.idtdna.com/calc/analyzer). If possible, primers should start and end with one or two G/C base pairs. The 3' end of the primer was most critical to accurately match the homologous regions of the majority of reference sequences. Few ambiguous base pairs were tolerated in the central region of the primer sequence and up to three ambiguity characters were introduced for $\leq 70 \%$ conserved sites per primer. Since accurate primer design and positive prediction do not guarantee efficient, practical implementation, trial and error have to succeed. Amplification primers were screened with at least three study samples (cDNA templates), and if possible, in conjunction with already established pairing primers. Primer selection was based upon efficient PCR amplification yielding strong and clean single bands without smear or evidence of unspecific amplification products in at least one NFG PCR or at least $1 / 3$ of PCR reactions amplifying smaller regions. Out of $>70$ newly tested amplification primers, 26 primers passed the selection criteria (Results 3.2). Sequencing primers were screened with at least two study samples, i.e., bulk-amplified nested PCR products with single strong bands that enabled positive sequencing reactions using established sequencing primers. Out of $>90$ newly tested sequencing primers, 64 primers worked sufficiently to determine sequences $\geq 700 \mathrm{bp}$ in length (quality value $\geq 16$, Macrogen sequencing service, New York, NY, USA) from half of the test samples (Results 3.2) [33].

\subsection{PCR Amplification}

PCR reactions were performed with PrimeSTAR GXL DNA polymerase, (Clontech, Mountain View, CA, USA) or High-Fidelity Taq polymerase (Life Technologies, Carlsbad, CA, USA). For Prime polymerase, nested PCRs were performed in a total reaction volume of $25 \mu \mathrm{L}$ per sample containing 15.5 $\mu \mathrm{L}$ nuclease-free water, $5 \mu \mathrm{L}$ 5X PrimeSTAR GXL Buffer ( $\mathrm{Mg}^{2+}$ plus), $2.5 \mu \mathrm{L}$ dNTP mix $(2.5 \mathrm{mM}$ each), $0.5 \mu \mathrm{L}$ Prime polymerase, $0.5 \mu \mathrm{L}$ forward and reverse primers, and $1 \mu \mathrm{L} c \mathrm{cDNA}$. For the Taq polymerase, a total reaction volume of $25 \mu \mathrm{L}$ per sample constituted of $18.85 \mu \mathrm{L}$ nuclease-free water, $2.5 \mu \mathrm{L}$ buffer $10 \mathrm{X}, 1 \mu \mathrm{L} \mathrm{MgSO}_{4}, 0.5 \mu \mathrm{L}$ dNTPs, $0.15 \mu \mathrm{L}$ Taq polymerase, $0.5 \mu \mathrm{L}$ forward and reverse primers, and $1 \mu \mathrm{L}$ cDNA.

The PCR reactions were performed with the following cycling conditions: initial denaturation step of $30 \mathrm{~s}$ at $98{ }^{\circ} \mathrm{C}$ and 30 cycles of $10 \mathrm{~s}$ at $98{ }^{\circ} \mathrm{C}$ (denaturation), $15 \mathrm{~s}$ at $53{ }^{\circ} \mathrm{C}$ (annealing), and elongation at $68^{\circ} \mathrm{C}$ for $1 \mathrm{~min}$ per $1 \mathrm{~kb}$ of the amplification product. After 30 cycles, a final elongation step was performed at $68{ }^{\circ} \mathrm{C}$, and the mix stored at $4{ }^{\circ} \mathrm{C}$. The PCR products were analyzed by gel electrophoresis at $120 \mathrm{~V}$ for $30 \mathrm{~min}$ on a $0.8 \%$ agarose gel. To exclude/minimize unspecific amplification and cross-contamination, samples from different participants were processed separately or sequentially, and nucleotide removal treatments were applied frequently. Multiple sequence alignments (MEGA5.2) and highlighter plots (Los Alamos HIV Database) were done with current and historical PCR products from our lab to exclude cross-contamination.

\subsection{Sanger Sequencing and Sequence Editing}

Sanger Sequencing of amplified PCR products was done by Macrogen (Macrogen Corp., New York, NY, USA). Assembly and editing of the sequences were done with DNAStar package programs SeqMan Pro and EditSeq (Lasergene, Madison, WI, USA).

\subsection{Simplot and Recombinant Drawing Tool}

The Simplot software package version 3.2 (Window size 200, step size 20 and 250 bootstrap replicate) was used for breakpoint determination. Schematic illustrations of the various full genomes were done using the recombinant drawing tool provided by the Los Alamos HIV sequence database. 
A bootstrap support of $70 \%$ between a subtype reference strain and a query sequence was used as criteria to assign a subtype to a breakpoint region. If bootstrap values remained below $70 \%$ using several pure and CRF reference subtypes, the region was considered unidentified.

\subsection{Third-Generation Sequencing}

Third-generation sequencing (TGS) was performed using Oxford Nanopore MinIon flow cells, capable of high-throughput sequencing in real-time and generating long DNA reads. TGS was carried out at the NYU sequencing and genomic unit. Unsheared HIV DNA from 12 samples was quantitated with the qubit HS DNA kit (Thermo Fisher Scientific). DNA was normalized to $1 \mu \mathrm{g}$ in $45 \mathrm{uL}$ of buffer and individually input into the Oxford Nanopore PCR Barcoding kit (EXP-PBC001, R9 Version) according to the protocol outlined by Oxford Nanopore (PBGE_9007_V7_revA_16May2016। PBGE_9007_v7_revJ_16May2016). Each sample was barcoded with a unique adapter index provided in the kit (using the NEB LongAmp Taq master mix, NEB \# M0287S) and run with the following PCR conditions: Initial Denaturation for $3 \mathrm{~min}$ at $95^{\circ} \mathrm{C}$, Denaturation for $15 \mathrm{~s}$ at $95^{\circ} \mathrm{C}$, Annealing for $15 \mathrm{~s}$ at $62{ }^{\circ} \mathrm{C}$, Extension for $12 \mathrm{~min}$ at $65^{\circ} \mathrm{C}$, Denaturation to Extension was repeated for an additional 14 cycles to compensate for the large fragment sizes (15 cycles total), and one final extension at the end for $14 \mathrm{~min}$ at $65^{\circ} \mathrm{C}$. After PCR, each sample was cleaned with Ampure XP (Beckman Coulter) and barcoded samples were quantitated with the Qubit HS DNA kit. Twelve samples were normalized to $110 \mathrm{ng}$ each and combined into one pool for input into the Nanopore Sequencing kit from Oxford Nanopore (SQK-NSK007). The library prep was followed, as described in the protocol above. The pooled library was eluted for $30 \mathrm{~min}$ at $37^{\circ} \mathrm{C}$. The final library was quantitated with the qubit HS DNA kit and added onto a primed SpotON Flow Cell (Oxford Nanopore, \#FLO-MIN105). The SpotON Flow cell was run on the MinION Mk 1 (\#MIN-MAP002) with the script NC_48Hr_Sequencing_Run_FLO_MIN105. FASTQ files were generated using poretools (version 0.6.0) (PMID: 25143291) and general quality controls were performed. Barcodes were trimmed using cutadapt (version 1.9.1) (http://journal.embnet.org/index.php/embnetjournal/article/view/200) and all the reads were mapped to HIV-I (HXB2) reference genome (K03455.1) for an initial quality assessment using the Burrows-Wheeler Aligner (BWA) (version 0.7.13) mem algorithm [34] and visualized using Integrative Genomics Viewer (IGV) software packages [35]. Phylogenetic analyses were done using MEGA5.2 software [36]. Maximum likelihood phylogenetic trees were generated using 1000 bootstrap replicates [37]. Any HIV unspecific reads or minor HIV variants that clustered with a viral population from an unrelated sample were removed. TGS (sub)populations were averaged to consensus (con) sequences using Consensus Maker (Los Alamos National Library (LANL) Database) (www.hiv.lanl.gov) or SeqMan Pro.

\subsection{Single-Gnome Amplification}

Single genome amplifications (SGA) are PCRs performed on endpoint-diluted cDNA to preclude amplification artifacts such as template switching that can occur when mixtures of genetically diverse templates are used. Template cDNA dilutions that resulted in no more than $30 \%$ positive nested PCR reactions were assumed to contain one amplifiable cDNA template per positive PCR $(>80 \%$ likelihood) [31]. Specifically, ten nested PCR reactions were performed per cDNA dilution. Multiple cDNA dilutions in the range between 1:2 and 1:1,000,000 were tested for each sample. Dilutions with no more than three positive PCR reactions were considered for SGA analyses and the positive amplicons subjected to direct sequencing. SGAs were performed using High-Fidelity PrimeSTAR GXL DNA polymerase (Clontech, Mountain View, CA, USA) using the same PCR and cycling conditions as described under 2.5 . 


\subsection{Cloning}

PCR products were ligated into pcDNA3.1 (blunt-end cloning, PrimeSTAR PCR products) or PCR4 TOPO (3'-A overhang cloning, Taq PCR products) cloning vectors (Life Technologies, Carlsbad, CA, USA). The plasmids were subsequently transformed into One Shot Top10 Chemically Competent E. coli, (Life Technologies, Carlsbad, CA, USA) and cultured overnight using LB-ampicillin agar plates [38].

\subsection{Data Storage and Documentation}

Near full genome sequences are available from GenBank with accession numbers MK086109-MK086132. Whole sets of TGS sequences are available upon request. Correspondence, data and material requests should be addressed to Ralf Duerr (Ralf.Duerr@nyumc.org).

\section{Results}

\subsection{Design of an Adaptable NFG Amplification Strategy}

The goal was to establish a flexible and straightforward methodology for NFG amplification, cloning, and sequencing applicable to the broad variety of group $\mathrm{M}$ subtypes and recombinant forms. The protocol should be suitable for several downstream methods including high-throughput sequencing (NGS or TGS), SGA, cloning, and bulk sequencing, and applicable to modern practice in well-equipped labs as well as to basic procedures in resource-limited countries. The NFGS approaches aimed to cover $>8.5 \mathrm{~kb}$ including all encoding HIV- $1 \mathrm{M}$ genes, i.e., from gag to $n e f$. The primary goal was the reliable and consistent determination of NFGS of highly diverse group M strains irrespective of the number of amplicons needed (Figure 1). The first option was the amplification of HIV-1 NFG in a single PCR using primers targeting the 5' UTR and 3' UTR regions. Also, we established a two-amplicon and multiple-amplicon approach. The two-amplicon approach targeted two overlapping "half genome" (HG) sequences. The 5' HG region (HG1) included gag and pol, while the 3' HG region (HG2) included $e n v$ and $n e f$. The accessory genes (vif, $v p r, v p u$ ) were included in both half genomes in their overlapping part. The multiple amplicon strategies aimed to cover near full genomes using three to five overlapping amplicons from a selection of eight PCR constructs in total. Each PCR construct encompassed complete genomic units of encoding genes (env also separated into gp120 and gp41). 


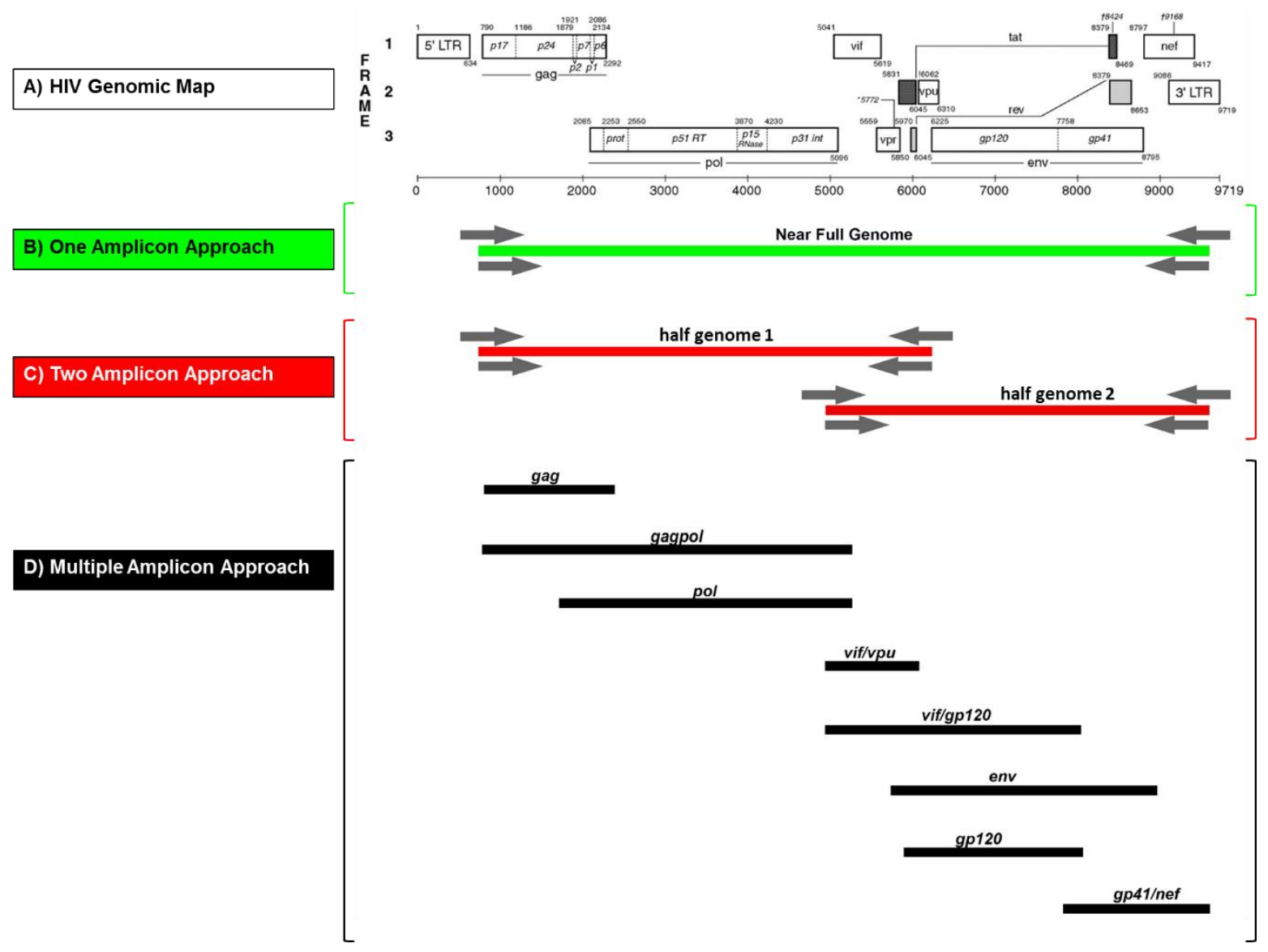

Figure 1. Near full genome sequence amplification approaches. (A) Genome map of HIV-1 reference strain HxB2 (GenBank: K03455). (B) One-amplicon approach to obtain a single 9.1 kb PCR fragment (near full genome) shown in green. (C) Two-amplicon approach with two overlapping PCR fragments (shown in red), with half genome 1 (HG1) $5.2 \mathrm{~kb}$ and half genome 2 (HG2) $4.6 \mathrm{~kb}$ in size. (D) Multiple-amplicon approach: Selection of eight overlapping PCR fragments (shown in black), i.e. gag (1.5 kb), gagpol (4.5 kb), pol (3.2 kb), vifopu (1.5 kb), vif/gp120 (3 kb), env (3.4 kb), gp120 (1.7 kb) and gp41/nef (1.8 kb). Positions of primers are schematically shown with gray arrows in (A) and (B).

\subsection{Rational Primer Design for NFG Amplification and Sequencing of Diverse Group M Viruses}

NFGS approaches on our highly diverse Cameroonian URF samples had only limited success using published NFG primers $[16,25]$ (see below). Therefore, rational primer design was performed using full genome reference sequence alignments with diverse HIV-1 group M strains downloaded from the LANL database (Table 1). Initially, an alignment composed of 480 reference sequences was used belonging to several known pure and CRF clades covering the major branches of each subtype [32]. 
Table 1. Amplification primers.

\begin{tabular}{|c|c|c|c|c|c|c|}
\hline Portion Analyzed & Nested PCR Round & Primer ID & Sequence & Position in $\mathrm{HxB2}$ & Temp. & Reference \\
\hline \multirow{4}{*}{ Near full genome 1 (NFG1) } & \multirow{2}{*}{ 1st Round } & 5' UTR_For1 & TGCCTTGAGTGCTTCAAGTAGTGTG & $536-560$ & $58.4^{\circ} \mathrm{C}$ & This study \\
\hline & & 3' UTR_Rev1 & TATTGAGGCTTAAGCAGTGGGTTC & $9615-9592$ & $57^{\circ} \mathrm{C}$ & This study \\
\hline & \multirow{2}{*}{ 2nd Round } & 5' UTR_For2 & TCTGTTGTGTGACTCTGGTAACTAGAGATC & $567-596$ & $58.7^{\circ} \mathrm{C}$ & This study \\
\hline & & 3' UTR_Rev4 & GCTCAAATCTGGTCTAGCAAGAGAGA & $9567-9542$ & $58^{\circ} \mathrm{C}$ & This study \\
\hline \multirow{4}{*}{ Near full genome 2 (NFG2) } & \multirow{2}{*}{ 1st Round } & HIV_682_For & TCTCTCGACGCAGGACTCGGCTTGCTG & $682-708$ & $67^{\circ} \mathrm{C}$ & [25] \\
\hline & & HIV_9555_Rev & TCTACCTAGAGAGACCCAGTACA & 9555-9533 & $55.5^{\circ} \mathrm{C}$ & [25] \\
\hline & \multirow[b]{2}{*}{ 2nd Round } & HIV_776_For & CTAGAAGGAGAGAGAGATGGGTGCGAG & $776-800$ & $61^{\circ} \mathrm{C}$ & [25] \\
\hline & & HIV_9555_Rev & TCTACCTAGAGAGACCCAGTACA & $9555-9533$ & $55.5^{\circ} \mathrm{C}$ & [25] \\
\hline \multirow{4}{*}{ Near full genome 3 (NFG3) } & \multirow{2}{*}{ 1st Round } & HIV_682_For & TCTCTCGACGCAGGACTCGGCTTGCTG & $682-708$ & $67^{\circ} \mathrm{C}$ & [25] \\
\hline & & 3' UTR_Rev3 & AGAGCTCCCAGGCTCAAATCTGGTCTA & $9578-9552$ & $62.5^{\circ} \mathrm{C}$ & This study \\
\hline & \multirow{2}{*}{ 2nd Round } & HIV_776_For & CTAGAAGGAGAGAGAGATGGGTGCGAG & $776-800$ & $61{ }^{\circ} \mathrm{C}$ & [25] \\
\hline & & 3' UTR_Rev4 & GCTCAAATCTGGTCTAGCAAGAGAGA & $9567-9542$ & $58^{\circ} \mathrm{C}$ & This study \\
\hline \multirow{4}{*}{ Near full genome 4 (NFG4) } & \multirow[b]{2}{*}{ 1st Round } & HIV_682_For & TCTCTCGACGCAGGACTCGGCTTGCTG & $682-708$ & $67^{\circ} \mathrm{C}$ & [25] \\
\hline & & 3' UTR_Revev5 & CAGTACAGGCGAGAAGCAGCTGCT & $9539-9516$ & $62{ }^{\circ} \mathrm{C}$ & This Study \\
\hline & \multirow{2}{*}{ 2nd Round } & HIV_776_For & CTAGAAGGAGAGAGAGATGGGTGCGAG & $776-800$ & $61^{\circ} \mathrm{C}$ & [25] \\
\hline & & 3' UTR_Rev6 & AGCAGCTGCTTATATGCAGCATCTGAG & 9525-9499 & $60.7^{\circ} \mathrm{C}$ & This Study \\
\hline \multirow{4}{*}{ Half genome 1a (HG1a) } & \multirow{2}{*}{ 1st Round } & HIV_682_For & TCTCTCGACGCAGGACTCGGCTTGCTG & $682-708$ & $67^{\circ} \mathrm{C}$ & [25] \\
\hline & & Vpu2_Rev & CCGCTTCTTCCTGCCATAGGA & $5985-5966$ & $59.1^{\circ} \mathrm{C}$ & This study \\
\hline & \multirow{2}{*}{ 2nd Round } & HIV_776_For & CTAGAAGGAGAGAGAGATGGGTGCGAG & $776-800$ & $61^{\circ} \mathrm{C}$ & {$[25]$} \\
\hline & & Vpu3_Rev & TCCTGCCATAGGAGATGCCTAAG & $5978-5956$ & $58.1^{\circ} \mathrm{C}$ & This study \\
\hline \multirow{4}{*}{ Half genome 1b (HG1b) } & \multirow{2}{*}{ 1st Round } & Gag3_For & GAGAGATGGGTGCGAGAGC & $785-803$ & $57^{\circ} \mathrm{C}$ & This study \\
\hline & & Vpu2_Rev & CCGCTTCTTCCTGCCATAGGA & $5985-5966$ & $59.1^{\circ} \mathrm{C}$ & This study \\
\hline & \multirow{2}{*}{ 2nd Round } & Gag4_For & TAGTATGGGCAAGCAGGGA & $890-908$ & $56{ }^{\circ} \mathrm{C}$ & This study \\
\hline & & Vpu3_Rev & TCCTGCCATAGGAGATGCCTAAG & $5978-5956$ & $58.1^{\circ} \mathrm{C}$ & This study \\
\hline \multirow{4}{*}{ Half genome 2 (HG2) } & \multirow{2}{*}{ 1st Round } & Vif2_For & TGGAAAGGTGAAGGGGCAGTA & $4956-4976$ & $58.4^{\circ} \mathrm{C}$ & This study \\
\hline & & OFM19 & GCACTCAAGGCAAGCTTTATTGAGGCTTA & $9632-9604$ & $60.9^{\circ} \mathrm{C}$ & {$[31]$} \\
\hline & \multirow{2}{*}{ 2nd Round } & Vif3_For & GATTATGGAAAACAGATGGCAGGT & $5037-5060$ & $55.2^{\circ} \mathrm{C}$ & This study \\
\hline & & HIV_9555_Rev & TCTACCTAGAGAGACCCAGTACA & $9555-9533$ & $55.5^{\circ} \mathrm{C}$ & [25] \\
\hline \multirow{4}{*}{ gagpol } & \multirow{2}{*}{ 1st Round } & Gag2_For & GACTAGCGGAGGCTAGAAG & $764-782$ & $54^{\circ} \mathrm{C}$ & This study \\
\hline & & Pol2_Rev & CCATGTTCTAATCCTCATCCTGTC & $5103-5080$ & $55^{\circ} \mathrm{C}$ & This study \\
\hline & \multirow[b]{2}{*}{ 2nd Round } & Gag3_For & GAGAGATGGGTGCGAGAGC & $785-803$ & $57^{\circ} \mathrm{C}$ & This study \\
\hline & & Pol3_Rev & CTGTCTACCTGCCACACA & $5084-5067$ & $54{ }^{\circ} \mathrm{C}$ & This study \\
\hline
\end{tabular}


Table 1. Cont

\begin{tabular}{|c|c|c|c|c|c|c|}
\hline Portion Analyzed & Nested PCR Round & Primer ID & Sequence & Position in $\mathrm{HxB2}$ & Temp. & Reference \\
\hline \multirow{4}{*}{ gag } & \multirow{2}{*}{ 1st Round } & Gag2_For & GACTAGCGGAGGCTAGAAG & $764-782$ & $54^{\circ} \mathrm{C}$ & This study \\
\hline & & Gag1_Rev & ССААТТСССССТАТСАТ & $2404-2388$ & $48^{\circ} \mathrm{C}$ & This study \\
\hline & \multirow[b]{2}{*}{ 2nd Round } & Gag4_For & TAGTATGGGCAAGCAGGGA & 890-908 & $56^{\circ} \mathrm{C}$ & This study \\
\hline & & Gag3_Rev & GGTCGTTGCCAAAGAGTGA & $2278-2260$ & $55^{\circ} \mathrm{C}$ & This study \\
\hline \multirow{4}{*}{ pol } & \multirow{2}{*}{ 1st Round } & Pol1_For & GAAGAAATGATGACAGC & 1819-1835 & $45^{\circ} \mathrm{C}$ & This Study \\
\hline & & Pol1_Rev & TGCCAGTCTCTTTCTCCTG & $5279-5161$ & $54^{\circ} \mathrm{C}$ & This study \\
\hline & \multirow{2}{*}{ 2nd Round } & Pol2_For & AAGTGTTTCAACTGTGG & 1960-1976 & $47^{\circ} \mathrm{C}$ & This study \\
\hline & & Pol2_Rev & CCATGTTCTAATCCTCATCCTGTC & $5103-5080$ & $55^{\circ} \mathrm{C}$ & This study \\
\hline \multirow{4}{*}{ vifopu } & \multirow{2}{*}{ 1st Round } & Vif 1_For & GGGTTTATTACAGGGACAGCAGAG & $4900-4923$ & $57.3^{\circ} \mathrm{C}$ & [31] \\
\hline & & Vpu1_Rev & TTGCCACTYTCTTCTGCTCTTTC & $6225-6203$ & $56.4^{\circ} \mathrm{C}$ & This study \\
\hline & \multirow{2}{*}{ 2nd Round } & Vif 2_For & TGGAAAGGTGAAGGGGCAGTA & $4956-4976$ & $58.4^{\circ} \mathrm{C}$ & This study \\
\hline & & Vpu2_Rev & CCGCTTCTTCCTGCCATAGGA & $5985-5966$ & $59.1^{\circ} \mathrm{C}$ & This study \\
\hline \multirow{4}{*}{ vif/gp120 } & \multirow{2}{*}{ 1st Round } & Vif1_For & GGGTTTATTACAGGGACAGCAGAG & $4900-4923$ & $57.2^{\circ} \mathrm{C}$ & This study \\
\hline & & Gp120out & GCARCCCCAAAKYCCTAGG & $8018-8000$ & $57.2{ }^{\circ} \mathrm{C}$ & This study \\
\hline & \multirow{2}{*}{ 2nd Round } & Vif2_For & TGGAAAGGTGAAGGGGCAGTA & $4956-4976$ & $58.4^{\circ} \mathrm{C}$ & This study \\
\hline & & Gp120in & CGTCAGCGTYATTGACGCYGC & $7838-7818$ & $61.4^{\circ} \mathrm{C}$ & This study \\
\hline \multirow{4}{*}{ env } & \multirow{2}{*}{ 1st Round } & Vif1_For & GGGTTTATTACAGGGACAGCAGAG & $4900-4923$ & $57.2^{\circ} \mathrm{C}$ & [31] \\
\hline & & OFM19 & GCACTCAAGGCAAGCTTTATTGAGGCTTA & $9632-9604$ & $60.9^{\circ} \mathrm{C}$ & [31] \\
\hline & \multirow{2}{*}{ 2nd Round } & Env A & (CACC)GGCTTAGGCATCTCCTATGGCAGGAAGAA & $5954-5982$ & $63{ }^{\circ} \mathrm{C}$ & [31] \\
\hline & & 02AG-Env N & GTTCTGCCAATCTGGGAAGAATCCTTGTGTG & 9174-9144 & $62.3^{\circ} \mathrm{C}$ & This study \\
\hline \multirow{4}{*}{ gp120 } & \multirow{2}{*}{ 1st Round } & Env A & GGCTTAGGCATCTCCTATGGCAGGAAGAA & $5954-5982$ & $62.8^{\circ} \mathrm{C}$ & [31] \\
\hline & & Gp120out & GCARCCCCAAAKYCCTAGG & $8018-8000$ & $57.2^{\circ} \mathrm{C}$ & [39] \\
\hline & \multirow{2}{*}{ 2nd Round } & Env B & AGAAAGAGCAGAAGACAGTGGCA & $6202-6224$ & $58.2{ }^{\circ} \mathrm{C}$ & [31] \\
\hline & & Gp120in & CGTCAGCGTYATTGACGCYGC & $7838-7818$ & $61.4^{\circ} \mathrm{C}$ & [39] \\
\hline \multirow{4}{*}{ gp41/nef } & \multirow{2}{*}{ 1st Round } & Gp120in_For1 & CAGCAGGAAGCACTATGGGCG & $7798-7818$ & $60.7^{\circ} \mathrm{C}$ & This study \\
\hline & & 3’UTR_Rev1 & TATTGAGGCTTAAGCAGTGGGTTC & 9615-9592 & $57^{\circ} \mathrm{C}$ & This study \\
\hline & \multirow{2}{*}{ 2nd Round } & Gp120in_For2 & GCRGCGTCAATRACGCTGACG & $7818-7838$ & $61.4^{\circ} \mathrm{C}$ & This study \\
\hline & & 3’UTR_Rev4 & GCTCAAATCTGGTCTAGCAAGAGAGA & 9567-9542 & $58^{\circ} \mathrm{C}$ & This study \\
\hline
\end{tabular}


Subsequently, the alignment was reduced and simplified to a representative 40 strain-panel comprising four reference sequences per eight (sub)-subtypes A1, A2, B, C, D, F1, F2, G, and two CRFs, 01_AE, and 02_AG (Figure 2). The designed amplification primers mostly targeted conserved domains adjacent or at the ends of the HIV-1 $\mathrm{M}$ genes of interest under consideration of primer characteristics such as melting temperature, GC content and secondary structure (using IDT web application and/or PrimerDesign-M, LANL database). The newly designed primers were combined with published primers $[25,31]$ that exhibited significant amplification efficiencies in our Cameroonian cohort (Table 1). The newly developed primers targeted regions in the HIV-1 M genome, which were highly conserved across several reference sequences of diverse subtypes, as shown for the NFG and two HG amplicon approaches (Figure 2; Figures S1 and S2). Of significant importance, the terminal nucleotides of the primer binding sites were highly conserved, whereas a few internal positions exhibited moderate variance for some primers/reference strains. The binding sites of three primers for half genome amplifications were fully conserved across the 40 reference strains panel (Figures S1 and S2). Overall, we designed/selected 26 new amplification primers, complemented by ten primers from previous studies $[25,31]$ that proved to be efficient. They were used for the amplification of 15 different constructs including four NFGs, three HGs, and eight smaller regions within the full genome (Figures 1 and 3, Table 1).

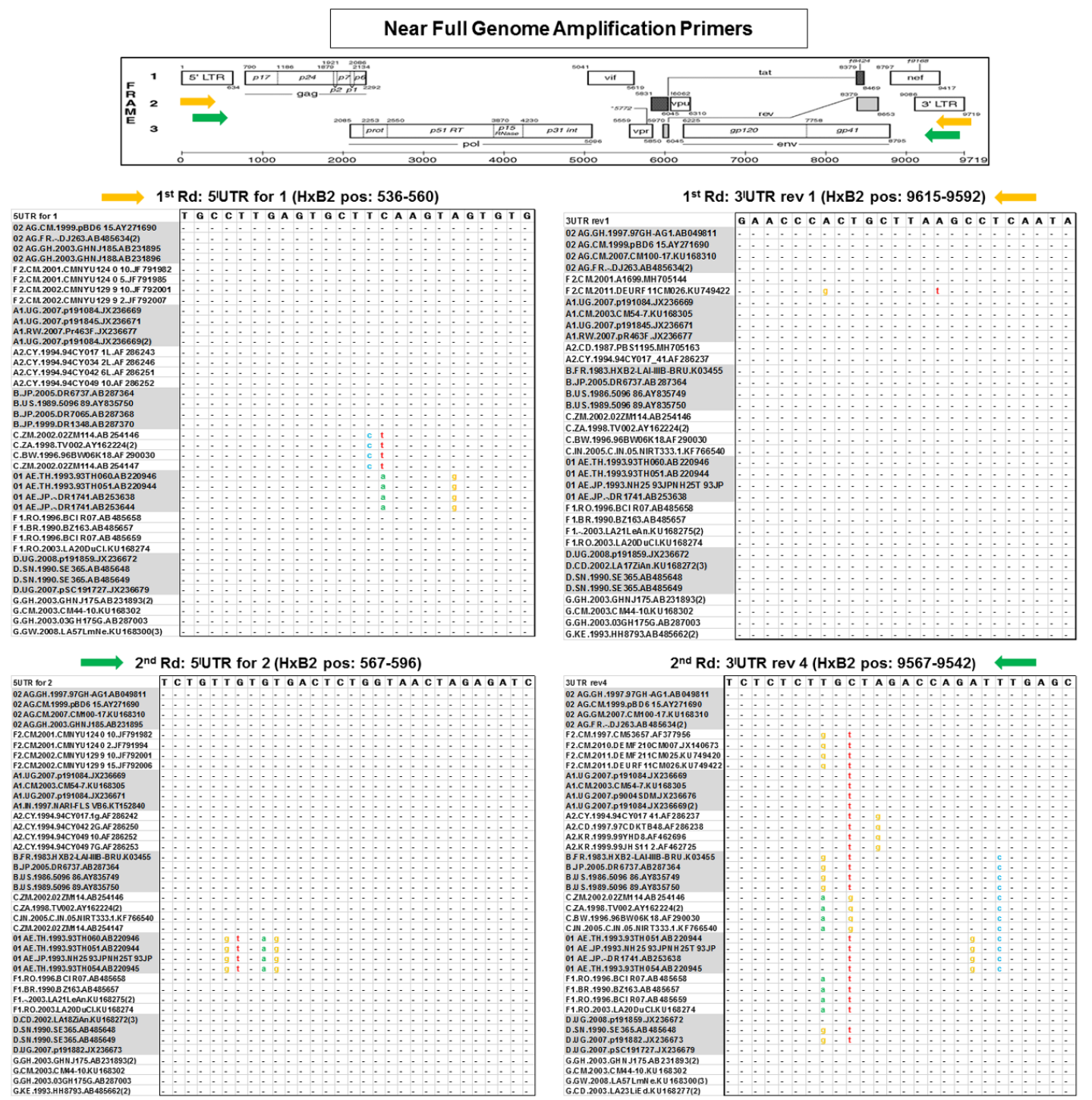


Figure 2. Conserved primer binding sites for HIV-1 near full genome amplification. Multiple sequence alignments of primer binding sites across ten different pure (sub)-subtypes and CRFs, as relevant for the near full genome amplification approach 1 . For each (sub)-subtype/CRF, four reference sequences were selected that broadly cover the respective clade; for the binding site of primer 3'UTR rev 1, only two A2 and F2 reference sequences were available from the LANL database. The numbering of primer binding regions is based on the HxB2 reference strain (GenBank: K03455). Positions (pos) of primer binding sites are shown in brackets (HxB2 pos. 596-9542). Orange and green arrows along the HxB2 genome map indicate first round and second round primer positions, respectively. Black dots and colored letters indicate matches and mismatches with primer nucleotides shown on top, respectively.

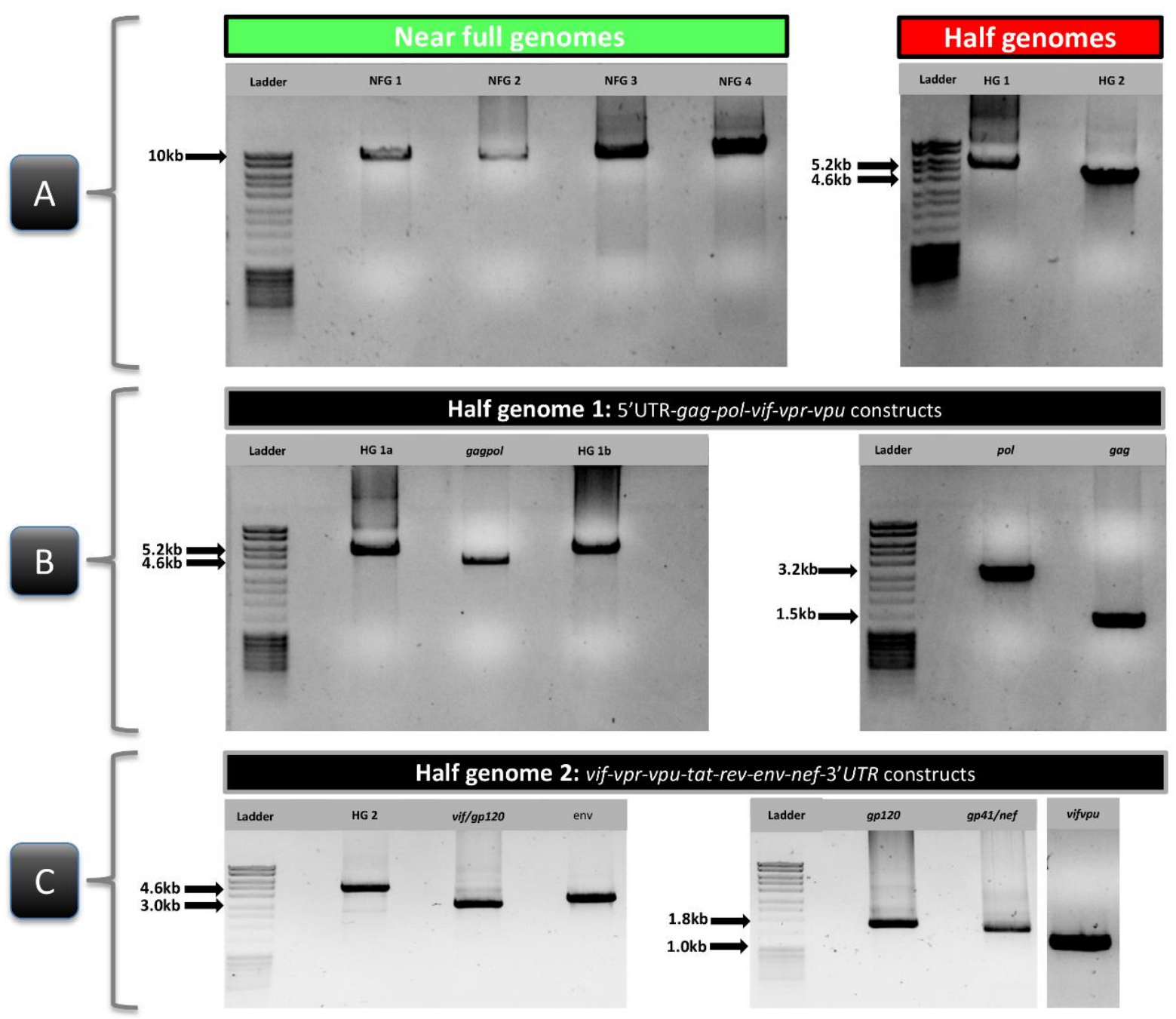

Figure 3. Gel electrophoresis of PCR products of different lengths for composite near full genome analysis. (A) HIV-1 near full genome (NFG; green) and half genome (HG; red) amplicons obtained with different primer sets. (B) Diverse amplicons within half genome 1 (HG1). (C) Diverse amplicons within half genome 2 (HG2). Amplicons were separated on an ethidium bromide-stained $0.8 \%$ agarose gel. MassRuler DNA ladder was used for amplicon size determination. The amplicons shown in the gels were obtained from the following samples: NYU6541-6 (NFG1), NYU129-5 (NFG2), LB089-1 (NFG3 and env), NYU1122-1 (NFG4, HG1, and HG1a), NYU119-3 (HG2, pol, and gag), NYU1999 (gagpol), NYU6556-3 (HG1b), BDHS33 (vif/gp120), NYU124-2 (gp120), and MDC131-1 (gp41/nef and vifopu).

Sequencing primers were designed based on the same criteria as described above for amplification primers. They were designed to generate fragments with $\geq 100 \mathrm{bp}$ overlap when sequences $\geq 700 \mathrm{bp}$ are obtained (Figure S3). Seventy-one sequencing primers were applied including 43 newly designed 
forward primers and 21 newly designed reverse primers, complemented by seven reverse primers published by other groups [25,31] (Tables 2 and 3).

Table 2. Forward sequencing primers.

\begin{tabular}{|c|c|c|c|c|}
\hline Primer ID & Sequence & Position in $\mathrm{HxB} 2$ & Temp. & Reference \\
\hline HIV_580_For & TCTGGTAACTAGAGATCC & $580-597$ & $46.6{ }^{\circ} \mathrm{C}$ & This study \\
\hline HIV_625_For & ATCTCTAGCAGTGGCGCCCGA & $625-641$ & $63^{\circ} \mathrm{C}$ & This study \\
\hline HIV_788_For & AGATGGGTGCGAGAGCGT & $788-809$ & $59.2{ }^{\circ} \mathrm{C}$ & This study \\
\hline HIV_1250_For & CATGGGTAAAGGTAATAGAAG & $1250-1270$ & $47.9^{\circ} \mathrm{C}$ & This study \\
\hline HIV_1250b_For & CATGGGTAAAAGTAATAGAA & $1250-1269$ & $44.5^{\circ} \mathrm{C}$ & This study \\
\hline HIV_1400_For & CCATCAATGAGGAAGCTGCA & 1400-1419 & $55.4{ }^{\circ} \mathrm{C}$ & This study \\
\hline HIV_1830_For & TGATGACAGCATGCCAGG & 1830-1847 & $55.3^{\circ} \mathrm{C}$ & This study \\
\hline HIV_1970_For & TTCAACTGTGGCAAAGAAGG & 1970-1989 & $53.4{ }^{\circ} \mathrm{C}$ & This study \\
\hline HIV_2075_For & GACAGGCTAATTTTTTAGGGA & 2075-2095 & $49.9^{\circ} \mathrm{C}$ & This study \\
\hline HIV_2590_For & CAGGAATGGATGGCCCAA & $2590-2607$ & $55.2{ }^{\circ} \mathrm{C}$ & This study \\
\hline HIV_2700_For & GGGCCTGAAAATCCATACAATACT & $2700-2723$ & $55.1^{\circ} \mathrm{C}$ & This study \\
\hline HIV_2756_For & GTACTAAATGGAGAAAATTAG & $2756-2776$ & $43.8^{\circ} \mathrm{C}$ & This study \\
\hline HIV_3300_For & AGCTGGACTGTCAATGA & $3300-3316$ & $50.4{ }^{\circ} \mathrm{C}$ & This study \\
\hline HIV_3350_For & GGGCAAGTCAAATTTATCCAG & $3350-3370$ & $51.8^{\circ} \mathrm{C}$ & This study \\
\hline HIV_3355_For & AGCCAGATTTATCCAGG & $3355-3371$ & $48.2{ }^{\circ} \mathrm{C}$ & This study \\
\hline HIV_4000_For & TAGCCTTGCAGGATTCAGGAT & $4000-4020$ & $56.0^{\circ} \mathrm{C}$ & This study \\
\hline HIV_4175_For & TGGAGGAAATGAACAAGTAGA & $4175-4195$ & $51^{\circ} \mathrm{C}$ & This study \\
\hline HIV_4542_For & GCAGGAAGATGGCCAGT & $4542-4558$ & $55.0^{\circ} \mathrm{C}$ & This study \\
\hline HIV_4646_For & TGGAATTCCCTACAATCC & -4663 & $48.6^{\circ} \mathrm{C}$ & This study \\
\hline HIV_4747_For & AGACAGCAGTACAGATGGCAG & $4747-4767$ & $56.7^{\circ} \mathrm{C}$ & This study \\
\hline HIV_4900_For & GGGTTTATTACAGGGACAGCA & $4900-4920$ & $54.6{ }^{\circ} \mathrm{C}$ & This study \\
\hline HIV_5388_For & TTTCAGAATCTGCCATAAG & $5388-5406$ & $47.1^{\circ} \mathrm{C}$ & This study \\
\hline HIV_5769_For & CATTTCAGAATYGGGTG & $5769-5786$ & $46.5^{\circ} \mathrm{C}$ & This study \\
\hline HIV_5840_For & GTAGATCCTARCCTAGA & 584 & $44.1^{\circ} \mathrm{C}$ & This study \\
\hline HIV_5970_For & ATGGCAGGAAGAAGCGGAGAC & $5970-5990$ & $59.5^{\circ} \mathrm{C}$ & This study \\
\hline HIV_6100_For & AGTAGCATTCATAGCAGCCAT & $6100-6120$ & $54.0^{\circ} \mathrm{C}$ & This study \\
\hline HIV_6125_For & GTGTGGACTATAGTATATATAG & $6125-6146$ & $44.1^{\circ} \mathrm{C}$ & This study \\
\hline HIV_63 & ATTTTGTGCATCAGATGC & & ${ }^{\circ} \mathrm{C}$ & This study \\
\hline HIV_6543_For & GATATAATTAGTCTATGGG & $6543-6561$ & $40.8^{\circ} \mathrm{C}$ & This study \\
\hline HIV_6745_For & CACTTTTTTATAGACTTGAT & $6745-6764$ & $42.7^{\circ} \mathrm{C}$ & This study \\
\hline HIV_6826_For & TTAMACAGGCTTGTCC & $6826-6841$ & $47.2{ }^{\circ} \mathrm{C}$ & This study \\
\hline HIV_6840_For & CCAAAGGTATCCTTTGAGCCA & $6840-6860$ & $54.9^{\circ} \mathrm{C}$ & This study \\
\hline HIV_6855_For & GAGCCAATTCCCATACAT & $6855-6872$ & $49.3^{\circ} \mathrm{C}$ & This study \\
\hline HIV_7500_For & ATGTGGCAGAAAGTAGGACAAGC & $7500-7522$ & $57.1^{\circ} \mathrm{C}$ & This study \\
\hline HIV_7520_For & AGCAATGTATGCCССТC & $7520-7536$ & $52{ }^{\circ} \mathrm{C}$ & This study \\
\hline HIV_7633_For & CTGGAGGAGGAGATATGAG & $7633-7651$ & $50.7^{\circ} \mathrm{C}$ & This study \\
\hline HIV_7660_For & GGAGAAGTGAATTATATAA & $7660-7678$ & $40.6^{\circ} \mathrm{C}$ & This study \\
\hline HIV_7803_For & GGAAGCACTATGGGCGC & $7803-7819$ & $56.7^{\circ} \mathrm{C}$ & This study \\
\hline HIV_8800_For & GGTGGCAAGTGGTCAAA & $8800-8816$ & $53.0^{\circ} \mathrm{C}$ & This study \\
\hline HIV_8180_For & GCAGGAAAAGAATGAACAAG & $8180-8199$ & $49.7^{\circ} \mathrm{C}$ & This study \\
\hline HIV_8970_For & GGTTAGAAGCACAAGAG & $8970-8986$ & $47.0^{\circ} \mathrm{C}$ & This study \\
\hline HIV_9015_For & GGTACCTTTAAGACCAATGA & $9015-9034$ & $49.3^{\circ} \mathrm{C}$ & This study \\
\hline HIV_9030_For & GACCAATGACTTATAAGG & $9030-9047$ & $44.1^{\circ} \mathrm{C}$ & This study \\
\hline
\end{tabular}

Fourteen sequencing primers were most frequently used based on their broad reactivity with our diverse study samples (Figure S3). These 14 primers provided complete sequence coverage from HxB2 positions 596 to 9604 ( 9.1 kb) in NFG one-amplicon approaches. For two-amplicon approaches, eight primers were used to sequence the 1st HG (HxB2 position 776 to $5956 ; \sim 5.2 \mathrm{~kb}$ ) and six primers for the 2nd HG (HxB2 position 5037 to $9533 ; \sim 4.6 \mathrm{~kb}$ ). 
Table 3. Reverse Sequencing Primer.

\begin{tabular}{|c|c|c|c|c|}
\hline Primer ID & Sequence & Position in $\mathrm{HxB2}$ & Temp. & Reference \\
\hline HIV_809_Rev & ACGCTCTCGCACCCATCT & $809-792$ & $58.9^{\circ} \mathrm{C}$ & This Study \\
\hline HIV_912_Rev & TCCCTGCTTGCCCATACTA & $912-894$ & $55.6^{\circ} \mathrm{C}$ & This study \\
\hline HIV_1270_Rev & СТТСТАТТАСТТТТАСССАТG & $1270-1250$ & $45.9^{\circ} \mathrm{C}$ & This study \\
\hline HIV_1505_Rev & GTTCCTGCTATRTCACTTCC & 1505-1486 & $51.5^{\circ} \mathrm{C}$ & This study \\
\hline HIV_2095_Rev & TCCСТAAAAAATTAGCCTGTC & 2095-2075 & $50.2{ }^{\circ} \mathrm{C}$ & This study \\
\hline HIV_3577_Rev & TGATAAATTTGATATGTCCA & $3577-3558$ & $43.9^{\circ} \mathrm{C}$ & This study \\
\hline HIV_5060_Rev & ACCTGCCATCTGTTTTCCATA & $5060-5040$ & $54.2{ }^{\circ} \mathrm{C}$ & This study \\
\hline HIV_5537_Rev & ACACTAGGCAAAGGYGG & $5537-5521$ & $53.5^{\circ} \mathrm{C}$ & This study \\
\hline HIV_6352_Rev & GGTACCCCATAATAGACTGTRACCCACAA & $6352-6324$ & $59.9{ }^{\circ} \mathrm{C}$ & [25] \\
\hline HIV_6764_Rev & ATCAAGTCTATAAAAAAGTG & $6764-6745$ & $42.7^{\circ} \mathrm{C}$ & This study \\
\hline HIV_6841_Rev & GGACAAGCCTGTKTAA & $6841-6826$ & $47.2{ }^{\circ} \mathrm{C}$ & This study \\
\hline HIV_6867_Rev & TGGGAATTGGCTCAAA & $6867-6852$ & $48.1^{\circ} \mathrm{C}$ & This study \\
\hline HIV_6904_Rev & TTTAGAATCGCAAAACCAGC & $6904-6885$ & $51.4^{\circ} \mathrm{C}$ & This study \\
\hline HIV_7025_Rev & TTCTGCTAGRCTGCCATT & $7025-7008$ & $52.4{ }^{\circ} \mathrm{C}$ & This study \\
\hline HIV_7085_Rev & CTGTACTATTATGGTTT & $7085-7069$ & $39.1^{\circ} \mathrm{C}$ & This study \\
\hline HIV_7351_Rev & AAACTATGTGTTGTAATTTC & $7351-7332$ & $43.5^{\circ} \mathrm{C}$ & This study \\
\hline HIV_7819_Rev & GCGCCCATAGTGCTTCC & $7819-7803$ & $56.7^{\circ} \mathrm{C}$ & This study \\
\hline HIV_7845_Rev & CCYGTACCGTCAGCGT & $7845-7830$ & $56^{\circ} \mathrm{C}$ & This study \\
\hline HIV_8075_Rev & TTTTTACACCGTCTAG & $8075-8059$ & $42^{\circ} \mathrm{C}$ & This study \\
\hline HIV_8448_Rev & TGTCTTGCTCKCCACCT & $8448-8432$ & $42{ }^{\circ} \mathrm{C}$ & This study \\
\hline HIV_8528_Rev & GTAGCTGAAGAGGCACAG & $8528-8511$ & $54.9{ }^{\circ} \mathrm{C}$ & This study \\
\hline HIV_8529_Rev & GGTAGCTGAAGAGGCACAGG & $8529-8510$ & $52.6^{\circ} \mathrm{C}$ & This study \\
\hline REV14 & ACCATGTTATTTTTCCACATGTTAAA & $6526-6501$ & $54.6^{\circ} \mathrm{C}$ & [31] \\
\hline REV15 & CTGCCATTTAACAGCAGTTGAGTTGA & $7015-6990$ & $57.8^{\circ} \mathrm{C}$ & [31] \\
\hline REV 16 & ATGGGAGGGGCATACATTGCT & $7540-7520$ & $59^{\circ} \mathrm{C}$ & [31] \\
\hline REV 17 & CCTGGAGCTGTTTAATGCCCCAGAC & $7956-7932$ & $61.7^{\circ} \mathrm{C}$ & [31] \\
\hline REV 18 & GGTGAGTATCCCTGCCTAACTCTAT & $8365-8341$ & $57.2{ }^{\circ} \mathrm{C}$ & [31] \\
\hline REV 19 & ACTTTTTGACCACTTGCCACCCAT & $8820-8797$ & $59.6{ }^{\circ} \mathrm{C}$ & [31] \\
\hline
\end{tabular}

\subsection{Subtype-Independent Amplification and Sequencing of HIV-1 Near Full Genomes}

Initially, we screened published NFGS nested primers for suitability with our cohort samples from Cameroon. Nested PCRs with a primer set previously optimized for NFGS of clade $C$ viruses [16] did not result in any NFG PCR products using three study samples including \#6541-6, which worked for most other NFGS approaches tested in this study. However, using a nested primer set recently optimized for multiple HIV-1 subtypes [25], we obtained positive reactions for \#6541-6 and two more study samples out of 23 tested specimens (Table 4). Based on these results, we screened the newly designed primers as well as combinations of our and published primers to optimize NFGS across multiple HIV-1 group M subtypes (Table 1).

To establish and optimize the method, we first used four study samples from infections with pure (sub)-subtype viruses (B and F2; \#Strain0526 and \#LB002-1), a CRF (CRF02_AG; \#6506-8), and a URF (\#6541-6) (based on preliminary and published partial genome sequencing data of Duerr and Nyambi labs $[29,40]$ ) (Figure 4). Subtypes F2 and CRF02_AG were chosen, because of their high prevalence in Cameroon [41]. Two of those constructs could be amplified with a one-amplicon approach, the other two with a two-amplicon approach (Table 4). Subsequently, we analyzed 19 more samples, including another subtype F2 virus (\#LB022), another CRF02_AG virus (\#LB006-1), and different highly diverse URF samples from Cameroon (Table 4). The 18 URF genomes were composed of subtypes A (A1), F (F2), G, and recombinants CRF01_AE, CRF02_AG, and CRF22_01A1, and revealed non-uniform mosaic NFG sequences [27]. 
Table 4. Summary of amplification approaches and yield using 23 pure or recombinant HIV-1 samples.

\begin{tabular}{|c|c|c|c|c|c|c|c|c|c|c|c|c|}
\hline & & $\begin{array}{l}\text { Near Full } \\
\text { Genome } 1\end{array}$ & $\begin{array}{l}\text { Near Full } \\
\text { Genome } 2\end{array}$ & $\begin{array}{l}\text { Near Full } \\
\text { Genome } 3\end{array}$ & $\begin{array}{l}\text { Near Full } \\
\text { Genome } 4\end{array}$ & $\begin{array}{c}\text { Half } \\
\text { Genome 1a }\end{array}$ & $\begin{array}{c}\text { Half } \\
\text { Genome 1b }\end{array}$ & $\begin{array}{c}\text { Half } \\
\text { Genome } 2\end{array}$ & gagpol & vif/gp120 & env & $g p 120$ \\
\hline $\begin{array}{l}\text { Sample } \\
\text { ID }\end{array}$ & $\begin{array}{c}\text { 1st Rd } \\
\text { Primers } \\
\text { 2nd Rd } \\
\text { Primers } \\
\end{array}$ & $\begin{array}{l}\text { 5'UTRfor1/ } \\
\text { 3'UTRrev1 } \\
\text { 5'UTRfor2/ } \\
\text { 3'UTR rev4 }\end{array}$ & $\begin{array}{l}\text { HIV682for/ } \\
\text { HIV9555rev } \\
\text { HIV776for/ } \\
\text { HIV9555rev }\end{array}$ & $\begin{array}{l}\text { HIV682for/ } \\
\text { 3'UTRrev3 } \\
\text { HIV776for/ } \\
\text { 3'UTR rev4 }\end{array}$ & $\begin{array}{l}\text { HIV682for/ } \\
\text { 3'UTRrev5 } \\
\text { HIV776for/ } \\
\text { 3'UTR rev6 }\end{array}$ & $\begin{array}{l}\text { HIV682for/ } \\
\text { Vpu2 rev } \\
\text { HIV776for/ } \\
\text { Vpu3rev } \\
\end{array}$ & $\begin{array}{l}\text { Gag3for/ } \\
\text { Vpu2 rev } \\
\text { Gag4for/ } \\
\text { Vpu3 rev }\end{array}$ & $\begin{array}{c}\text { Vif2for/ } \\
\text { OFM19 } \\
\text { Vif3for/ } \\
\text { HIV9555rev } \\
\end{array}$ & $\begin{array}{l}\text { Gag2for/ } \\
\text { pol2 rev } \\
\text { Gag3for/ } \\
\text { pol3rev }\end{array}$ & $\begin{array}{c}\text { Vif1for/ } \\
\text { Gp120out } \\
\text { Vif2for/ } \\
\text { Gp120in }\end{array}$ & $\begin{array}{c}\text { Vif1/ } \\
\text { OFM19 } \\
\text { EnvA/ } \\
\text { 02AG-EnvN } \\
\end{array}$ & $\begin{array}{c}\text { EnvA/ } \\
\text { Gp120out } \\
\text { EnvB/ } \\
\text { Gp120in }\end{array}$ \\
\hline \multicolumn{2}{|c|}{ LB016-1 } & positive & - & - & - & positive & positive & positive & - & positive & positive & positive \\
\hline \multicolumn{2}{|c|}{ LB069-1 } & positive & - & - & - & - & positive & positive & positive & - & positive & positive \\
\hline \multicolumn{2}{|c|}{ LB082-1 } & - & - & - & - & - & positive & positive & positive & positive & positive & positive \\
\hline \multicolumn{2}{|c|}{ LB089-1 } & positive & - & positive & - & - & positive & positive & positive & positive & positive & positive \\
\hline \multicolumn{2}{|c|}{ LB095-1 } & positive & - & - & - & positive & positive & positive & positive & - & positive & positive \\
\hline \multicolumn{2}{|c|}{ LB104-1 } & - & - & - & - & - & positive & positive & - & positive & - & positive \\
\hline \multicolumn{2}{|c|}{ MDC131-1 } & - & - & - & - & positive & - & positive & positive & - & - & - \\
\hline \multicolumn{2}{|c|}{ MDC179-2 } & - & - & - & - & - & positive & positive & positive & positive & - & - \\
\hline \multicolumn{2}{|c|}{ BDHS24-2 } & - & - & - & - & - & positive & positive & positive & positive & positive & positive \\
\hline \multicolumn{2}{|c|}{ BDHS33 } & - & - & - & - & - & - & positive & positive & positive & - & positive \\
\hline \multicolumn{2}{|c|}{ NYU119-3 } & - & - & - & - & positive & positive & positive & - & positive & - & positive \\
\hline \multicolumn{2}{|c|}{ NYU124-2 } & - & - & - & - & positive & positive & positive & - & positive & positive & positive \\
\hline \multicolumn{2}{|c|}{ NYU129-5 } & - & positive & - & - & - & positive & positive & positive & - & positive & positive \\
\hline \multicolumn{2}{|c|}{ NYU1122-1 } & - & positive & - & positive & positive & positive & positive & - & positive & - & positive \\
\hline \multicolumn{2}{|c|}{ NYU1999 } & - & - & - & - & - & positive & positive & positive & - & - & positive \\
\hline \multicolumn{2}{|c|}{ NYU2140-1 } & - & - & - & - & positive & - & positive & - & positive & positive & positive \\
\hline \multicolumn{2}{|c|}{ NYU6556-3 } & - & - & - & positive & - & positive & positive & positive & positive & positive & - \\
\hline \multicolumn{2}{|c|}{ NYU6541-6 } & positive & positive & positive & positive & positive & positive & positive & - & positive & positive & positive \\
\hline \multicolumn{2}{|c|}{ NYU6506-8 } & - & - & - & - & - & positive & positive & - & - & - & - \\
\hline \multicolumn{2}{|c|}{ Strain0526 } & - & - & - & - & positive & - & positive & - & - & - & - \\
\hline \multicolumn{2}{|c|}{ LB002-1 } & - & - & positive & - & NA & NA & NA & NA & NA & NA & NA \\
\hline \multicolumn{2}{|c|}{ LB022-1 } & - & - & positive & - & NA & NA & NA & NA & NA & NA & NA \\
\hline \multicolumn{2}{|c|}{ LB006-1 } & - & - & - & positive & NA & NA & NA & NA & NA & NA & NA \\
\hline \multicolumn{13}{|c|}{ Miscellaneous HIV-1 genome regions amplified } \\
\hline & & gag & pol & vifopu & gp120 & gp41/nef & & & & & & \\
\hline & $\begin{array}{c}\text { 1st Rd } \\
\text { primers }\end{array}$ & $\begin{array}{l}\text { Gag2for/ } \\
\text { Gag1 rev }\end{array}$ & $\begin{array}{l}\text { Pol1for/ } \\
\text { Pol1rev }\end{array}$ & $\begin{array}{l}\text { Vif1for/ } \\
\text { Vpu1rev }\end{array}$ & $\begin{array}{c}\text { EnvA/ } \\
\text { Gp120out }\end{array}$ & $\begin{array}{l}\text { Gp120in for1/ } \\
\text { 3'UTRrev1 }\end{array}$ & & & & & & \\
\hline $\begin{array}{l}\text { Sample } \\
\text { ID }\end{array}$ & $\begin{array}{l}\text { 2nd Rd } \\
\text { primers }\end{array}$ & $\begin{array}{l}\text { Gag4for/ } \\
\text { Gag3rev }\end{array}$ & $\begin{array}{l}\text { Pol2for/ } \\
\text { Pol2rev }\end{array}$ & $\begin{array}{l}\text { Vif2for/ } \\
\text { Vpu2rev }\end{array}$ & $\begin{array}{l}\text { EnvB/ } \\
\text { Gp120in }\end{array}$ & $\begin{array}{c}\text { Gp120in for2/ } \\
\text { 3'UTRrev4 }\end{array}$ & & & & & & \\
\hline MDC & $131-1$ & positive & positive & positive & NA & positive & & & & & & \\
\hline NYL & $119-3$ & positive & positive & positive & positive & positive & & & & & & \\
\hline NYL & $124-2$ & positive & positive & positive & positive & positive & & & & & & \\
\hline
\end{tabular}




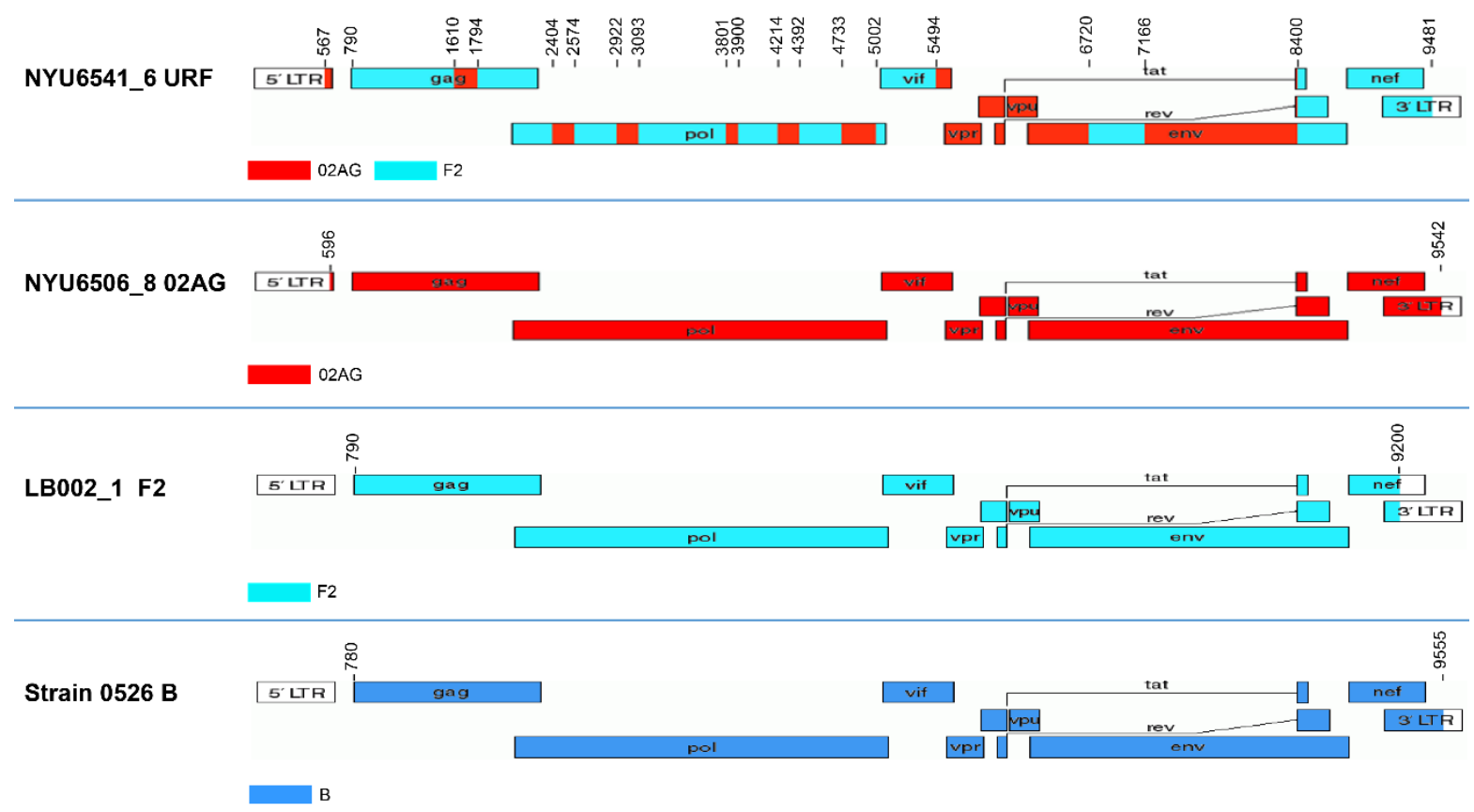

Figure 4. Development of a near full genome sequencing approach using recombinant and pure subtype strains. Genome maps of four HIV-1 strains, which were used to develop the near full genome sequencing approach. The determined subtypes are indicated using the recombinant drawing tool of the LANL database. NYU6541_6, NYU6506_8, LB002_1 and strain 0526 correspond to a unique recombinant form (URF), the circulating recombinant form CRF02_AG, sub-subtype F2, and subtype $\mathrm{B}$, respectively.

Out of 23 samples, 11 NFGS were obtained with a one-amplicon approach. Another 11 samples needed two amplicons and one sample at least three amplicons for NFGS determination (Table 4). The one-amplicon approaches were based on nested PCRs with primers targeting the 5' UTR and 3' UTR ends to obtain approximately $9.1 \mathrm{~kb}$ products in a single PCR reaction (Figure 1). The four optimized NFGS primer pairs (NFG1 to NFG 4) obtained yields between 13\% and $21.7 \%$ (Table 1; Table 4); the best yield was obtained with the NFG1 approach based on four newly designed primers (21.7\% yield). Only one sample (\#6541-6) could be amplified using all four NFGS approaches (Table 4). The four one-amplicon approaches complemented each other to an overall $43 \%$ yield. In the two-amplicon approach, NFGS were obtained from two overlapping half genomes. Half genome 1 (HG1) consisted of gag, pol and the accessory genes vif, vpr, and $v p u(\sim 5.2 \mathrm{~kb})$, whereas the second half genome (HG2) included vif, vpr, vpu, env, and nef ( 4.6 kb) (Figure 1 and Table 1). HG1a and b had $45 \%$ and $80 \%$ yield, respectively, and complemented each other except for one sample, to achieve a $95 \%$ yield in combination. Of interest, HG2, which was obtained using a mix of newly designed primers and published primers [25,31] achieved 100\% yield and proved to be the most efficient nested primer combination in our set of study samples (Table 4). The amplification of smaller regions for the multiple-amplicon approach included gag (1.5 kb), gagpol (4.5 kb), pol (3.2 kb), vifvpu (1.0 kb), vif/gp120 $(3.0 \mathrm{~kb})$, env (3.4 kb), gp120 (1,7 kb), and $g p 41 / n e f(1.8 \mathrm{~kb})$ (Figure 1; Tables 1 and 4) with yields $>55 \%$. Since plasma viral load (PVL) has been described as a critical parameter for successful NFG sequencing $[16,17,21]$, we analyzed whether the viral load of a sample predicted the number of amplicons needed for characterizing the NFG. Using the diverse study set of Cameroonian URF viruses, no association was observed between the number of amplicons needed for NFGS and PVL (Figure S4). The lowest PVL in our set of study samples with determined NFGS was $306 \mathrm{cps} / \mathrm{mL}$. 


\subsection{Comparative NFGS Analysis Using Different Amplification, Cloning, and Sequencing Strategies}

To validate our NFGS approach, different amplification, cloning, and sequencing procedures including bulk amplification, high-throughput/deep sequencing, and SGA were applied. The NFGS outcome was compared across platforms using sample NYU6541-6, which gave positive results for most amplification approaches. Bulk sequencing is the traditional method for the genetic determination of viral variants that make up $\geq 20 \%$ of a viral population in a sample, e.g., it is still the standard for genotypic drug resistance testing [41,42]. High-throughput sequencing enables more in-depth analyses and can assess the diversity of viral populations in a sample. As proof of principle, we used the portable MinION TGS technology (Oxford Nanopore Technologies) with the capacity to determine long reads in real-time [43]. Despite limitations in accuracy and depth [44,45], it gave an estimate of whether our diverse amplicon approaches are suited for high-throughput/deep sequencing (Figure 5 and Table 5) [27].

\section{Bootscan Plots of NYU6541_6}
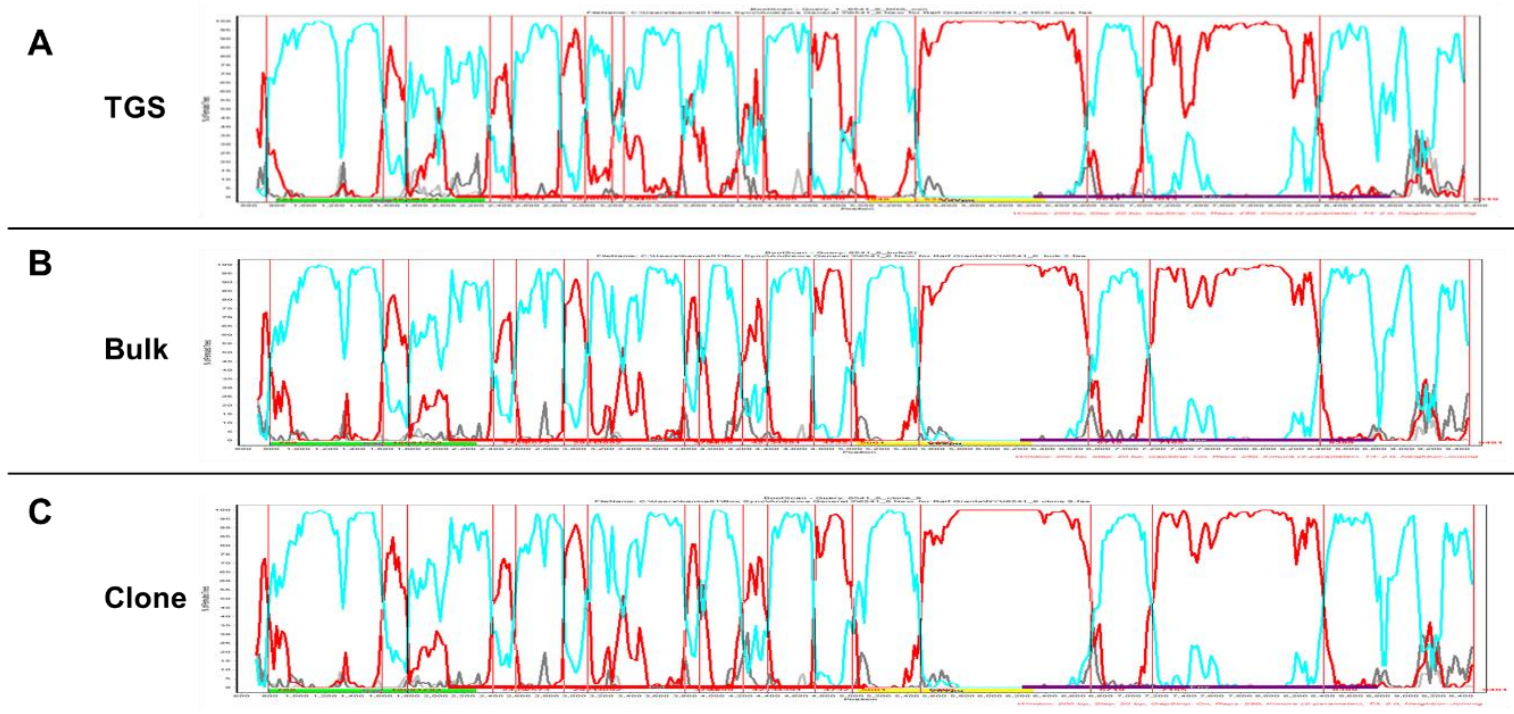

D SGA

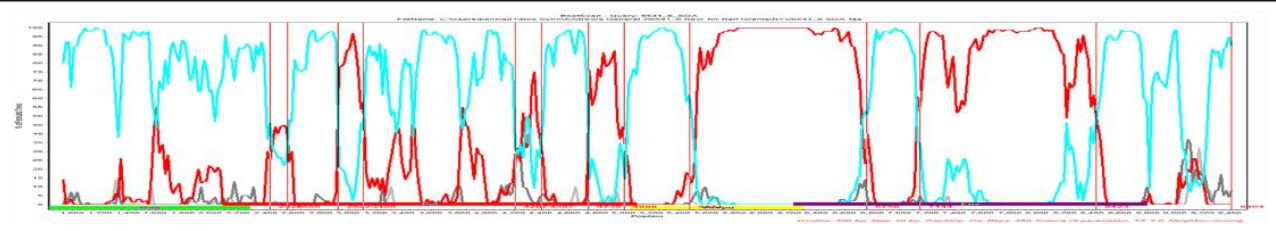

Figure 5. Comparative recombinant breakpoint analysis of near full genome sequences obtained with four different amplification, sequencing, and cloning strategies. Using sample NYU6541_6, different amplification, sequencing, and cloning techniques were studied: (A) third-generation sequencing (TGS), (B) bulk amplification and Sanger sequencing, (C) cloning after bulk amplification, followed by Sanger sequencing, and (D) single genome amplification (SGA) and Sanger sequencing. BootScan plots (Simplot software) are shown for near full genome sequences of NYU6541_6 with window size 200 and step size 20. Breakpoint patterns were determined by analyzing the query sequence against CRF02_AG (red), F2 (cyan), C (dark gray), and B (light gray) reference strains. The genomic regions gag, pol, vif/opr/opu and env are schematically shown along the x-axis in green, red, yellow, and purple bars, respectively. The $y$-axis indicates bootstrap values obtained after 250 replicative measurements. 
Table 5. Summary of third-generation sequencing (TGS) and single-genome amplification (SGA).

\begin{tabular}{|c|c|c|c|c|c|c|}
\hline$\#$ & Sample ID & $\begin{array}{c}\text { TGS } \\
\text { Total Number of HIV Reads }\end{array}$ & $\begin{array}{c}\text { TGS } \\
\text { Average Read Length }\end{array}$ & $\begin{array}{c}\text { TGS } \\
\text { Number of Long HIV Reads }\end{array}$ & $\begin{array}{c}\text { TGS } \\
\text { Genomic Region }\end{array}$ & $\begin{array}{c}\text { SGA } \\
\text { Genomic Region }\end{array}$ \\
\hline 1 & LB016-1 & 713 & 1731 & $17(>5000 \mathrm{bp})$ & Near full genome 1 & NA \\
\hline 2 & LB069-1 & 1701 & 3929 & $488(>5000 \mathrm{bp})$ & Near full genome 1 & NA \\
\hline 3 & LB082-1 & 610 & 4232 & $179(>4000 \mathrm{bp})$ & Half genome 2 & Half genome 2 \\
\hline 4 & LB089-1 & NA & NA & NA & NA & NA \\
\hline 5 & LB095-1 & NA & NA & NA & NA & Half genome 2 \\
\hline 6 & LB104-1 & 1120 & 3830 & $61(>4000 \mathrm{bp})$ & Half genome 2 & NA \\
\hline 7 & MDC131-1 & NA & NA & NA & NA & NA \\
\hline 8 & MDC179-2 & 1956 & 2807 & $504(>2000 \mathrm{bp})$ & vif/gp120 & NA \\
\hline 9 & BDHS024-2 & 3463 & 4047 & 799 (>4000 bp) & Half genome 2 & NA \\
\hline 10 & BDHS33 & 3184 & 4122 & $813(>4000 \mathrm{bp})$ & Half genome 2 & NA \\
\hline 11 & NYU119-3 & NA & NA & NA & NA & NA \\
\hline 12 & NYU124-2 & 2076 & 2837 & 964 (>2000 bp) & vif/gp120 & NA \\
\hline 13 & NYU129-5 & NA & NA & NA & NA & Half genome 2 \\
\hline 14 & NYU1122-1 & 2648 & 2478 & $752(>2000 \mathrm{bp})$ & vif/gp120 & NA \\
\hline 15 & NYU1999-1 & NA & NA & NA & NA & NA \\
\hline 16 & NYU2140-1 & 2108 & 4044 & $448(>4000 \mathrm{bp})$ & Half genome 2 & NA \\
\hline 17 & NYU6556-3 & NA & NA & NA & NA & Half genome 2 \\
\hline 18 & NYU6541-6 & 262 & 1415 & $41(>5000 \mathrm{bp})$ & Near full genome 1 & Near full genome 1 \\
\hline 19 & NYU6506-8 & NA & NA & NA & NA & NA \\
\hline 20 & Strain0526 & NA & NA & NA & NA & Half genome 2 \\
\hline 21 & LB002-1 & NA & NA & NA & NA & NA \\
\hline 22 & LB022-1 & NA & NA & NA & NA & NA \\
\hline 23 & LB006-1 & NA & NA & NA & NA & NA \\
\hline
\end{tabular}


Since amplification artifacts such as recombination events can occur in vitro during bulk amplification, single genome amplification (SGA) [31] was used for validation of our results. Six samples were tested for SGA including NFG and HG constructs. Our results confirmed the results reported by other groups $[46,47]$ that major viral populations detected by deep or bulk sequencing show a good match with SGA sequences with comparable genetic coverage (Figure 5 and Table 5) [27]. Specifically, in vitro recombination rates $<1.6 \%$ were reported for bulk amplification [46,47]. As a precaution, TGS minority variants with $<2 \%$ prevalence that were not confirmed by SGA were consequently excluded in our analyses. In contrast to high-throughput sequencing such as NGS or TGS, bulk sequencing and SGA allow the cloning of NFG constructs, which enables further functional characterization in downstream biological assays, such as replicative fitness or phylogenetic drug resistance tests [48-50]. An NFGS plasmid generated by Topo cloning of an NFG bulk amplicon was included in the comparative analysis, which revealed comparable characteristics to bulk sequencing as evident by $<0.1 \%$ genetic distance and similar recombination breakpoint patterns (Figure 5). A comparative Simplot Bootscan analysis was performed to underline the significance of the introduced NFGS approach for accurate subtype/recombinant form determination across platforms. Bulk sequencing, cloning, SGA, and TGS (consensus sequence) yielded similar NFGS results with genetic distances $<2 \%$ across platforms and overall comparable recombinant breakpoints patterns (Figure 5).

\section{Discussion}

Here, we report a simple and efficient method for the amplification and sequencing of HIV-1 near full genomes from plasma to cover a broad range of recombinant (URF and CRF) viruses and pure group M (sub)-subtypes. Due to the flexible approach based on one, two, or more amplicons, $100 \%$ of the study samples were genotyped over the near full genome. Recent studies performing NFGS out of plasma achieved different efficiencies in the range of $45-100 \%$ [16-18,20-22,25,46], from which most approaches remained below $100 \%$ efficiency and/or were restricted to specific subtypes. A one-amplicon approach obtained $67 \%$ NFGS efficiency in a subtype C cohort [16], whereas a two-amplicon approach applied to samples of diverse clades yielded $90-92 \%$ success rates $[25,46]$. A study in a US clade B cohort used an alternative two- or three-amplicon strategy to obtain $76 \%$ yield for samples with viral loads $>10,000 \mathrm{cps} / \mathrm{mL}$. A four-amplicon strategy achieved $93 \%$ yield when applied to diverse HIV-1 subtypes and groups [21], however when used in an Indian cohort with clade $\mathrm{C}$ and AC recombinant samples, the yield dropped to $45 \%$ despite adjustments to an optimized six amplicon strategy [18]. The results of these studies imply and confirm our findings in achieving higher percentages of NFGS when diverse amplicon approaches are complementarily used. In our study, the $43 \%$ efficiency of the one-amplicon approach, based on four different NFG protocols, increased to $95 \%$ when a two-amplicon strategy based on two different half genome protocols was used, and eventually achieved $100 \%$ with the help of multiple amplicons. Two NGS-based methods were recently introduced, which also obtained $100 \%$ NFGS rates. They were applied in a clade B cohort using a four amplicon strategy [20] or in a highly diverse study population using mixed four- and six-amplicon NGS libraries [22]. The latter study used an elegant method based on degenerate primers fused to common adapter sequences for efficient library generation, which enabled broad coverage of HIV subtypes and groups; however, the need of NGS equipment and expert knowledge limits its application in resource-constrained countries. Also, the method required considerable optimizations with regards to RNA extraction and cDNA synthesis for suitability with clinical samples.

For NFGS, a viral load threshold of $3,000 \mathrm{cps} / \mathrm{mL}[16,21]$ or even $10,000 \mathrm{cps} / \mathrm{mL}[16,17,21]$ has been reported. NGS can generate full genome coverage at viral loads $>\log 3.5 \mathrm{cps} / \mathrm{mL}$, while even most sensitive NGS/probes approach gradually decline to partial genome coverage for $<\log 3.5 \mathrm{cps} / \mathrm{mL}$ [22,26]. Of interest, we obtained NFGS over a broad range of PVL down to $\sim 300 \mathrm{cps} / \mathrm{mL}$, although it is worth mentioning that in our study, we only had one sample below 3,000 cps/mL PVL included, and plasma was routinely concentrated $\sim 3.5$ fold (from $500 \mu \mathrm{L}$ to $140 \mu \mathrm{L}$ ) before RNA extraction. Other than that, our method needed no additional optimizations. Other groups reported that a substantially higher 
yield could be obtained using Benzonase pretreatment of plasma before RNA extraction to reduce the background of human RNA and DNA and by increasing the reverse transcription temperature from $42{ }^{\circ} \mathrm{C}$ to $47^{\circ} \mathrm{C}$ [22]. Doubling the amount of RT enzyme from $200 \mathrm{U}$ to $400 \mathrm{U}$ significantly increased the critical RT step for NFGS in another study [17].

Despite the limitation in sample size (23 subjects), the analysis of a range of pure (sub)-subtypes and recombinant forms including A (A1), B, F (F2), G, CRF01_AE, CRF02_AG, and CRF22_01A1 implies a broad applicability of the presented NFGS approach across diverse (sub)-subtypes/recombinants and geographic regions of the world. Universal usage of our approach is further corroborated by the set of primers, designed to bind several most prevalent pure (sub)-subtypes and recombinant forms on the globe. Nevertheless, future studies are needed to show that the primers and the NFGS strategy are robust on larger sample sets from diverse regions of the world. The introduced procedure of rational primer design coupled with a flexible amplicon strategy allows researchers to improve the protocol further according to their needs.

Our approach provides a universal toolbox that can be used and adapted for different amplification and sequencing applications and is easy to handle for laboratories in resource-limited countries. Besides the flexible methodology, it allows both NFGS as well as focused molecular studies for distinct genomic regions. Since our method does not necessarily depend on high-throughput sequencing (NGS/TGS), which usually determines a one-way road towards genetic read-out, the SGA or bulk amplification can be used for the generation of molecular clones and subsequent downstream applications in biological assays. Notably, the introduced combination of primers from different studies [25,31] including our newly designed primers brought up highly efficient nested PCR primer pairs that may prove useful for purposes beyond NFGS and subtype monitoring. For example, we achieved $100 \%$ yield in our HG2 approach, which includes the amplification of the complete env region and accessory genes. It could be a useful alternative for env SGA, pseudovirus generation, screening for neutralizing antibody resistant strains, and genotypic tropism analysis. Another construct encompassing whole pol, gag, and accessory genes (HG1b) was obtained with $80 \%$ amplification yield when using four newly designed nested primers. The latter represents a promising approach for genotypic drug resistance testing in research and clinical care covering several essential target sites. Although not tested in the present study, we expect our NFG amplification approaches to performing well with state-of-the-art NGS systems to capture minority variants in quasispecies populations, as we showed recently for the sensitive Illumina MiSeq platform using a related amplification approach restricted to the reverse transcriptase region of pol [41].

Hence, the proposed protocols have broad applicability and can form the basis for downstream applications in phylogenetic and molecular studies, and further project-specific optimizations of primer combinations. While the studied in-depth sequencing approach based on MinION technology needs further optimization regarding accuracy and depth, it indicates future implications in real-time NFGS on-site.

\section{Conclusions}

In summary, we designed and validated a robust and adaptable protocol for NFGS from plasma, capable of amplifying and sequencing a broad diversity of HIV-1 group M strains including pure (sub)-subtypes and mosaic viral strains (URF and CRF). Despite the limited number of 23 samples, our approach suggests broad applicability based on the semi-conserved primer design and the flexible amplicon approach. Future studies using larger sample numbers from different geographic regions and epidemics will need to confirm its suitability in global HIV surveillance. The introduced NFGS approach may prove valuable to complement existing strategies in structural and functional HIV research including regions with rapid evolution and emergence of novel recombinant viral strains.

Supplementary Materials: The following are available online at http://www.mdpi.com/1999-4915/11/4/317/s1, Figure S1: Conserved primer binding sites for HIV-1 half genome 1 amplification. Figure S2: Conserved primer binding sites for HIV-1 half genome 2 amplification. Figure S3: Stepwise sequencing approach. 
Figure S4: Correlation analysis between plasma viral load and the number of amplicons needed for near full genome sequencing.

Author Contributions: Conceptualization, R.D.; Formal analysis, A.N.B., M.T., M.T., A.K.-J., A.J.N., J.M., D.M., J.N., A.H., P.N.N., C.F. and R.D.; Investigation, A.N.B., M.T., J.S.B., P.Z. and X.W.; Project administration, A.J.N., D.M., A.H., P.N.N. and C.F.; Writing-original draft, A.N.B. and R.D.; Writing-review \& editing, A.N.B. and R.D

Funding: This research was funded by grant number AI083142 from the National Institute of Allergy and Infectious Diseases and grant number TW009604 from the Fogarty International Center, National Institutes of Health. This research was also supported by the Sub-Saharan African Network for TB/HIV Research Excellence (SANTHE), a DELTAS Africa Initiative (grant \# DEL-15-006). The DELTAS Africa Initiative is an independent funding scheme of the African Academy of Sciences (AAS)'s Alliance for Accelerating Excellence in Science in Africa (AESA) and supported by the New Partnership for Africa's Development Planning and Coordinating Agency (NEPAD Agency) with funding from the Welcome Trust (grant \# 107752/Z/15/Z) and the UK government.

Acknowledgments: The authors thank the individuals who consented to participate and donated their blood samples for this study. Our appreciation is extended to the Cameroon Ministry of Public Health for supporting this study. Thanks further go to Caroline Kakam, Bladine Asaah, and Flavia Camacho for their assistance in sample collection and manuscript preparation.

Conflicts of Interest: The authors declare no conflict of interest.

\section{References}

1. Gurtler, L.G.; Hauser, P.H.; Eberle, J.; von Brunn, A.; Knapp, S.; Zekeng, L.; Tsague, J.M.; Kaptue, L. A new subtype of human immunodeficiency virus type 1 (MVP-5180) from Cameroon. J. Virol. 1994, 68, 1581-1585.

2. Plantier, J.C.; Leoz, M.; Dickerson, J.E.; de Oliveira, F.; Cordonnier, F.; Lemee, V.; Damond, F.; Robertson, D.L.; Simon, F. A new human immunodeficiency virus derived from gorillas. Nat. Med. 2009, 15, 871-872. [CrossRef]

3. Vallari, A.; Holzmayer, V.; Harris, B.; Yamaguchi, J.; Ngansop, C.; Makamche, F.; Mbanya, D.; Kaptue, L.; Ndembi, N.; Gurtler, L.; et al. Confirmation of putative HIV-1 group P in Cameroon. J. Virol. 2011, 85, 1403-1407. [CrossRef] [PubMed]

4. Keele, B.F.; Van Heuverswyn, F.; Li, Y.; Bailes, E.; Takehisa, J.; Santiago, M.L.; Bibollet-Ruche, F.; Chen, Y.; Wain, L.V.; Liegeois, F.; et al. Chimpanzee reservoirs of pandemic and nonpandemic HIV-1. Science 2006, 313, 523-526. [CrossRef]

5. HIV Circulating Recombinant Forms (CRFs). Available online: https://www.hiv.lanl.gov/content/sequence/ HIV/CRFs/CRFs.html (accessed on 27 January 2019).

6. Hemelaar, J.; Elangovan, R.; Yun, J.; Dickson-Tetteh, L.; Fleminger, I.; Kirtley, S.; Williams, B.; Gouws-Williams, E.; Ghys, P.D.; Characterisation, W.-U.N.f.H.I. Global and regional molecular epidemiology of HIV-1, 1990-2015: A systematic review, global survey, and trend analysis. Lancet Infect. Dis. 2018. [CrossRef]

7. Reis, M.; Bello, G.; Guimaraes, M.L.; Stefani, M.M.A. Characterization of HIV-1 CRF90_BF1 and putative novel CRFs_BF1 in Central West, North and Northeast Brazilian regions. PLoS ONE 2017, 12, e0178578. [CrossRef]

8. Villabona Arenas, C.J.; Vidal, N.; Ahuka Mundeke, S.; Muwonga, J.; Serrano, L.; Muyembe, J.J.; Boillot, F.; Delaporte, E.; Peeters, M. Divergent HIV-1 strains (CRF92_C2U and CRF93_cpx) co-circulating in the Democratic Republic of the Congo: Phylogenetic insights on the early evolutionary history of subtype C. Virus Evol. 2017, 3, vex032. [CrossRef] [PubMed]

9. Miao, J.; Ran, J.; Song, Y.; Liu, Y.; Gao, L.; Miao, Z.; Zhang, C.; Feng, Y.; Xia, X. Characterization of a Novel HIV-1 Circulating Recombinant Form, CRF01_AE/B'/C (CRF96_cpx), in Yunnan, China. AIDS Res. Hum. Retroviruses 2017. [CrossRef] [PubMed]

10. Tongo, M.; Dorfman, J.R.; Martin, D.P. High Degree of HIV-1 Group M (HIV-1M) Genetic Diversity within Circulating Recombinant Forms: Insight into the Early Events of HIV-1M Evolution. J. Virol. 2015, 90, 2221-2229. [CrossRef]

11. Hemelaar, J. Implications of HIV diversity for the HIV-1 pandemic. J. Infect. 2013, 66, 391-400. [CrossRef] [PubMed]

12. Zhang, M.; Foley, B.; Schultz, A.K.; Macke, J.P.; Bulla, I.; Stanke, M.; Morgenstern, B.; Korber, B.; Leitner, T. The role of recombination in the emergence of a complex and dynamic HIV epidemic. Retrovirology 2010, 7, 25. [CrossRef] 
13. HIV Sequence Database. Available online: https://www.hiv.lanl.gov/content/sequence/HIV/mainpage.html (accessed on 27 January 2019).

14. Smyth, R.P.; Schlub, T.E.; Grimm, A.J.; Waugh, C.; Ellenberg, P.; Chopra, A.; Mallal, S.; Cromer, D.; Mak, J.; Davenport, M.P. Identifying recombination hot spots in the HIV-1 genome. J. Virol 2014, 88, 2891-2902. [CrossRef]

15. Fan, J.; Negroni, M.; Robertson, D.L. The distribution of HIV-1 recombination breakpoints. Infect. Genet. Evol. 2007, 7, 717-723. [CrossRef] [PubMed]

16. Rousseau, C.M.; Birditt, B.A.; McKay, A.R.; Stoddard, J.N.; Lee, T.C.; McLaughlin, S.; Moore, S.W.; Shindo, N.; Learn, G.H.; Korber, B.T.; et al. Large-scale amplification, cloning and sequencing of near full-length HIV-1 subtype C genomes. J. Virol. Methods 2006, 136, 118-125. [CrossRef] [PubMed]

17. Nadai, Y.; Eyzaguirre, L.M.; Constantine, N.T.; Sill, A.M.; Cleghorn, F.; Blattner, W.A.; Carr, J.K. Protocol for nearly full-length sequencing of HIV-1 RNA from plasma. PLoS ONE 2008, 3, e1420. [CrossRef] [PubMed]

18. Alampalli, S.V.; Thomson, M.M.; Sampathkumar, R.; Sivaraman, K.; U K J, A.J.; Dhar, C.; D Souza, G.; Berry, N.; Vyakarnam, A. Deep sequencing of near full-length HIV-1 genomes from plasma identifies circulating subtype $\mathrm{C}$ and infrequent occurrence of AC recombinant form in Southern India. PLoS ONE 2017, 12, e0188603. [CrossRef]

19. Alves, B.M.; Siqueira, J.D.; Garrido, M.M.; Botelho, O.M.; Prellwitz, I.M.; Ribeiro, S.R.; Soares, E.A.; Soares, M.A. Characterization of HIV-1 Near Full-Length Proviral Genome Quasispecies from Patients with Undetectable Viral Load Undergoing First-Line HAART Therapy. Viruses 2017, 9, 392. [CrossRef] [PubMed]

20. Henn, M.R.; Boutwell, C.L.; Charlebois, P.; Lennon, N.J.; Power, K.A.; Macalalad, A.R.; Berlin, A.M.; Malboeuf, C.M.; Ryan, E.M.; Gnerre, S.; et al. Whole genome deep sequencing of HIV-1 reveals the impact of early minor variants upon immune recognition during acute infection. PLoS Pathog. 2012, 8, e1002529. [CrossRef] [PubMed]

21. Gall, A.; Ferns, B.; Morris, C.; Watson, S.; Cotten, M.; Robinson, M.; Berry, N.; Pillay, D.; Kellam, P. Universal amplification, next-generation sequencing, and assembly of HIV-1 genomes. J. Clin. Microbiol. 2012, 50, 3838-3844. [CrossRef] [PubMed]

22. Berg, M.G.; Yamaguchi, J.; Alessandri-Gradt, E.; Tell, R.W.; Plantier, J.C.; Brennan, C.A. A Pan-HIV Strategy for Complete Genome Sequencing. J. Clin. Microbiol. 2016, 54, 868-882. [CrossRef]

23. Heipertz, R.A., Jr.; Ayemoba, O.; Sanders-Buell, E.; Poltavee, K.; Pham, P.; Kijak, G.H.; Lei, E.; Bose, M.; Howell, S.; O'Sullivan, A.M.; et al. Significant contribution of subtype G to HIV-1 genetic complexity in Nigeria identified by a newly developed subtyping assay specific for subtype G and CRF02_AG. Medicine (Baltimore) 2016, 95, e4346. [CrossRef]

24. Kijak, G.H.; Tovanabutra, S.; Sanders-Buell, E.; Watanaveeradej, V.; de Souza, M.S.; Nelson, K.E.; Ketsararat, V.; Gulgolgarn, V.; Wera-arpachai, M.; Sriplienchan, S.; et al. Distinguishing molecular forms of HIV-1 in Asia with a high-throughput, fluorescent genotyping assay, MHAbce v.2. Virology 2007, 358, 178-191. [CrossRef]

25. Grossmann, S.; Nowak, P.; Neogi, U. Subtype-independent near full-length HIV-1 genome sequencing and assembly to be used in large molecular epidemiological studies and clinical management. J. Int. AIDS Soc. 2015, 18, 20035. [CrossRef]

26. Yamaguchi, J.; Olivo, A.; Laeyendecker, O.; Forberg, K.; Ndembi, N.; Mbanya, D.; Kaptue, L.; Quinn, T.C.; Cloherty, G.A.; Rodgers, M.A.; et al. Universal Target Capture of HIV Sequences from NGS Libraries. Front. Microbiol. 2018, 9, 2150. [CrossRef] [PubMed]

27. Banin, A.N.; Tuen, M.; Tongo, M.; Bimela, J.S.; Nanfack, A.; Courtney, C.; Zappile, P.; Heguy, A.; Fokunang, C.; Mbanya, D.; Ngogang, J.; Nyambi, P.N.; Duerr, R. Near Full Genome Sequencing of Novel HIV-1 Unique Recombinant Forms Circulating in Cameroon. J. Int AIDS Soc. 2019. Submitted.

28. Courtney, C.R.; Agyingi, L.; Fokou, A.; Christie, S.; Asaah, B.; Meli, J.; Ngai, J.; Hewlett, I.; Nyambi, P.N. Monitoring HIV-1 Group M Subtypes in Yaounde, Cameroon Reveals Broad Genetic Diversity and a Novel CRF02_AG/F2 Infection. AIDS Res. Hum. Retroviruses 2016, 32, 381-385. [CrossRef]

29. Agyingi, L.; Mayr, L.M.; Kinge, T.; Orock, G.E.; Ngai, J.; Asaah, B.; Mpoame, M.; Hewlett, I.; Nyambi, P. The evolution of HIV-1 group M genetic variability in Southern Cameroon is characterized by several emerging recombinant forms of CRF02_AG and viruses with drug resistance mutations. J. Med. Virol. 2014, 86, 385-393. [CrossRef] 
30. Ragupathy, V.; Zhao, J.; Wood, O.; Tang, S.; Lee, S.; Nyambi, P.; Hewlett, I. Identification of new, emerging HIV-1 unique recombinant forms and drug resistant viruses circulating in Cameroon. Virol. J. 2011, 8, 185. [CrossRef]

31. Salazar-Gonzalez, J.F.; Bailes, E.; Pham, K.T.; Salazar, M.G.; Guffey, M.B.; Keele, B.F.; Derdeyn, C.A.; Farmer, P.; Hunter, E.; Allen, S.; et al. Deciphering human immunodeficiency virus type 1 transmission and early envelope diversification by single-genome amplification and sequencing. J. Virol 2008, 82, 3952-3970. [CrossRef] [PubMed]

32. Tongo, M.; Dorfman, J.R.; Abrahams, M.R.; Mpoudi-Ngole, E.; Burgers, W.A.; Martin, D.P. Near full-length HIV type $1 \mathrm{M}$ genomic sequences from Cameroon: Evidence of early diverging under-sampled lineages in the country. Evol. Med. Public Health 2015, 2015, 254-265. [CrossRef] [PubMed]

33. Ewing, B.; Hillier, L.; Wendl, M.C.; Green, P. Base-calling of automated sequencer traces using phred. I. Accuracy assessment. Genome Res. 1998, 8, 175-185. [CrossRef]

34. Li, H.; Durbin, R. Fast and accurate long-read alignment with Burrows-Wheeler transform. Bioinformatics 2010, 26, 589-595. [CrossRef] [PubMed]

35. Robinson, J.T.; Thorvaldsdottir, H.; Winckler, W.; Guttman, M.; Lander, E.S.; Getz, G.; Mesirov, J.P. Integrative genomics viewer. Nat. Biotechnol. 2011, 29, 24-26. [CrossRef] [PubMed]

36. Tamura, K.; Peterson, D.; Peterson, N.; Stecher, G.; Nei, M.; Kumar, S. MEGA5: Molecular evolutionary genetics analysis using maximum likelihood, evolutionary distance, and maximum parsimony methods. Mol. Biol. Evol. 2011, 28, 2731-2739. [CrossRef]

37. Tamura, K.; Dudley, J.; Nei, M.; Kumar, S. MEGA4: Molecular Evolutionary Genetics Analysis (MEGA) software version 4.0. Mol. Biol. Evol. 2007, 24, 1596-1599. [CrossRef] [PubMed]

38. Courtney, C.R.; Mayr, L.; Nanfack, A.J.; Banin, A.N.; Tuen, M.; Pan, R.; Jiang, X.; Kong, X.P.; Kirkpatrick, A.R.; Bruno, D.; et al. Contrasting antibody responses to intrasubtype superinfection with CRF02_AG. PLoS ONE 2017, 12, e0173705. [CrossRef]

39. Mayr, L.M.; Powell, R.L.; Ngai, J.N.; Takang, W.A.; Nadas, A.; Nyambi, P.N. Superinfection by discordant subtypes of HIV-1 does not enhance the neutralizing antibody response against autologous virus. PLoS ONE 2012, 7, e38989. [CrossRef]

40. Powell, R.L.; Urbanski, M.M.; Burda, S.; Nanfack, A.; Kinge, T.; Nyambi, P.N. Utility of the heteroduplex assay (HDA) as a simple and cost-effective tool for the identification of HIV type 1 dual infections in resource-limited settings. AIDS Res. Hum. Retroviruses 2008, 24, 100-105. [CrossRef] [PubMed]

41. Nanfack, A.J.; Redd, A.D.; Bimela, J.S.; Ncham, G.; Achem, E.; Banin, A.N.; Kirkpatrick, A.R.; Porcella, S.F.; Agyingi, L.A.; Meli, J.; et al. Multimethod Longitudinal HIV Drug Resistance Analysis in Antiretroviral-Therapy-Naive Patients. J. Clin. Microbiol 2017, 55, 2785-2800. [CrossRef] [PubMed]

42. Alidjinou, E.K.; Deldalle, J.; Hallaert, C.; Robineau, O.; Ajana, F.; Choisy, P.; Hober, D.; Bocket, L. RNA and DNA Sanger sequencing versus next-generation sequencing for HIV-1 drug resistance testing in treatment-naive patients. J. Antimicrob. Chemother. 2017, 72, 2823-2830. [CrossRef] [PubMed]

43. Jain, M.; Olsen, H.E.; Paten, B.; Akeson, M. The Oxford Nanopore MinION: Delivery of nanopore sequencing to the genomics community. Genome Biol. 2016, 17, 239. [CrossRef] [PubMed]

44. Laver, T.; Harrison, J.; O’Neill, P.A.; Moore, K.; Farbos, A.; Paszkiewicz, K.; Studholme, D.J. Assessing the performance of the Oxford Nanopore Technologies MinION. Biomol. Detect. Quantif. 2015, 3, 1-8. [CrossRef] [PubMed]

45. Tyler, A.D.; Mataseje, L.; Urfano, C.J.; Schmidt, L.; Antonation, K.S.; Mulvey, M.R.; Corbett, C.R. Evaluation of Oxford Nanopore's MinION Sequencing Device for Microbial Whole Genome Sequencing Applications. Sci. Rep. 2018, 8, 10931. [CrossRef] [PubMed]

46. Aralaguppe, S.G.; Siddik, A.B.; Manickam, A.; Ambikan, A.T.; Kumar, M.M.; Fernandes, S.J.; Amogne, W.; Bangaruswamy, D.K.; Hanna, L.E.; Sonnerborg, A.; et al. Multiplexed next-generation sequencing and de novo assembly to obtain near full-length HIV-1 genome from plasma virus. J. Virol. Methods 2016, 236, 98-104. [CrossRef]

47. Jordan, M.R.; Kearney, M.; Palmer, S.; Shao, W.; Maldarelli, F.; Coakley, E.P.; Chappey, C.; Wanke, C.; Coffin, J.M. Comparison of standard PCR/cloning to single genome sequencing for analysis of HIV-1 populations. J. Virol. Methods 2010, 168, 114-120. [CrossRef] [PubMed] 
48. Lu, J.; Sista, P.; Giguel, F.; Greenberg, M.; Kuritzkes, D.R. Relative replicative fitness of human immunodeficiency virus type 1 mutants resistant to enfuvirtide (T-20). J. Virol. 2004, 78, 4628-4637. [CrossRef] [PubMed]

49. Parrish, N.F.; Wilen, C.B.; Banks, L.B.; Iyer, S.S.; Pfaff, J.M.; Salazar-Gonzalez, J.F.; Salazar, M.G.; Decker, J.M.; Parrish, E.H.; Berg, A.; et al. Transmitted/founder and chronic subtype C HIV-1 use CD4 and CCR5 receptors with equal efficiency and are not inhibited by blocking the integrin alpha4beta7. PLoS Pathog. 2012, 8, e1002686. [CrossRef]

50. Weber, J.; Vazquez, A.C.; Winner, D.; Rose, J.D.; Wylie, D.; Rhea, A.M.; Henry, K.; Pappas, J.; Wright, A.; Mohamed, N.; et al. Novel method for simultaneous quantification of phenotypic resistance to maturation, protease, reverse transcriptase, and integrase HIV inhibitors based on 3'Gag(p2/p7/p1/p6)/PR/RT/INT-recombinant viruses: A useful tool in the multitarget era of antiretroviral therapy. Antimicrob. Agents Chemother. 2011, 55, 3729-3742. [CrossRef] [PubMed]

(C) 2019 by the authors. Licensee MDPI, Basel, Switzerland. This article is an open access article distributed under the terms and conditions of the Creative Commons Attribution (CC BY) license (http://creativecommons.org/licenses/by/4.0/). 